\title{
Host specialization in microparasites transmitted by generalist vectors: insights into the
} cellular and immunological mechanisms

(1)

\author{
Yi-Pin Lin ${ }^{1,2 \# *}$, Danielle M. Tufts ${ }^{3 \#}$, Alan P. Dupuis, $\mathrm{II}^{1}$, Matthew Combs ${ }^{3}$, Ashley L.
}

Marcinkiewicz ${ }^{1}$, Andrew D. Hirsbrunner ${ }^{1}$, Alexander J. Diaz ${ }^{1}$, Jessica L. Stout ${ }^{1}$, Anna M. Blom ${ }^{4}$, Klemen Strle ${ }^{1}$, April D. Davis ${ }^{1}$, Laura D. Kramer ${ }^{1,2}$, Maria A. Diuk-Wasser ${ }^{3 *}$

${ }^{1}$ Division of Infectious Diseases, Wadsworth Center, New York State Department of Health, Albany, NY, USA, ${ }^{2}$ Department of Biomedical Sciences, State University of New York at

Albany, NY, USA, ${ }^{3}$ Department of Ecology, Evolution, and Environmental Biology, Columbia University, New York, NY USA, ${ }^{4}$ Division of Medical Protein Chemistry, Department of Translational Medicine, Lund University, Malmo, Sweden

Short title: Early defense and pathogen adhesiveness confer spirochete host specialization

Key words: Lyme disease, Borrelia, Early immune responses, Adhesion

\section{${ }^{\#}$ Contributed equally to this work}

*correspondence: Yi-Pin Lin, Ph.D.

Division of Infectious Disease,

Wadsworth Center, New York State Department of Health 120 New Scotland Ave., Albany, NY 12047

Telephone: 518-402-2233; Fax: 518-473-1326

Email: Yi-Pin.Lin@health.ny.gov

*correspondence: Maria A. Diuk-Wasser, Ph.D.

Department of Ecology, Evolution, and Environmental Biology, Columbia University 1200 Amsterdam Ave., New York, NY 10027

Telephone: 212-854-3355

Email: $\underline{\operatorname{mad} 2256 @ \text { columbia.edu }}$ 


\section{ABSTRACT (289 words)}

Host specialization is an ecological and evolutionary process by which a pathogen becomes differentially adapted to a subset of hosts, restricting its host range. For parasites transmitted by generalist vectors, host specialization is not expected to evolve because of the decreased survival of those parasites in inadequate hosts. Thus, parasites may develop adaptation strategies, resulting in host specialization. The causative agents of Lyme disease are multiple species of bacteria, Borrelia burgdorferi sensu lato species complex (Bbsl), and are suitable for examining host specialization as birds and rodents were found to carry different species of these bacteria. Debate exists on whether host specialization occurs among these strains within a particular species of $B b s$, such as B. burgdorferi sensu stricto (Bbss). Current evidence supports some Bbss strains are widespread in white-footed mice but others are in non-rodent vertebrates, such as birds. To recapitulate specialization in the laboratory and define the mechanisms for host specialization, we introduced different genotypes of $B b$ ss via tick transmission to American robins and white-footed mice, the Lyme disease reservoirs in North America. Among these strains, we found distinct levels of spirochete presence in the bloodstream and tissues and maintenance by these animals in a hostdependent fashion. We showed that the late stage persistence of these strains largely corresponds to bacterial survival at early infection onsets. We also demonstrated that those early survival phenotypes correspond to spirochete adhesiveness, evasion of complement-mediated killing in sera, and/or not triggering high levels of pro-inflammatory cytokines and antibodies. Our findings thus link host competence to Bbss with spirochete genotypic variation of adhesiveness and inducing/escaping host immune responses, illuminating the potential mechanisms that dictate host specialization. Such information will provide a foundation for further investigation into multidisciplinary processes driving host specialization of microparasites. 


\section{AUTHOR SUMMARY (200 words)}

Host specialization arises when microparasites adapt to a subset of available hosts, restricting the host ranges they can infect. The mechanisms and selective pressures for the evolution of host specialization remain unclear. The causative agent of Lyme disease (LD), the bacteria species complex of Borrelia burgdorferi sensu lato, is adapted to different vertebrates. However, whether such a differential host adaption also applies to each genotype within the same species is under debate. Further, the mechanisms that drive such host specialization are unclear. We thus introduced three genotypes of one LD bacteria species (B. burgdorferi sensu stricto) individually via tick bite to American robins and white-footed mice, the most common LD reservoirs in North America. We found that these genotypes differed in the persistent maintenance by those reservoirs and occurred in a host-specific fashion. The ability of those bacteria for long-term maintenance was linked with their capability to attach to cells and a lack of induction of high levels of immune responses at early infection onsets. This work demonstrates the potential mechanisms that dictate host specialization of LD bacteria circulating in natural populations. Such information will pave the road to define the molecular, ecological, and evolutionary determinants that drive hostmicroparasite interactions.

67

68




\section{INTRODUCTION}

The range of hosts a parasite can infect is arguably one of the most important properties of a parasite because it can determine, among other things, whether a parasite can survive the extinction of a host species and whether it can become established and spread following its introduction to a new area $(1,2)$. Host specialization is defined as the ecological and evolutionary process by which a pathogen becomes differentially adapted and thus restricts its host range to a subset of potential hosts. For vector-borne microparasites, such a process is expected to evolve when vectors are specialized to competent hosts, leading to microparasite amplification. However, it is much less obvious how and when host specialization in a vector-borne microparasite can occur and when vectors are host-indiscriminate. Given the significant cost incurred when microparasites are inoculated into incompetent hosts, the evolution of host specialization is only expected to occur when it provides a significant selective advantage for the microparasite to overcome cellular or immunological barriers to infection.

The spirochetes of the B. burgdorferi sensu lato (s.1.) species complex, agents of Lyme disease, represent an ideal system to investigate the tradeoffs involved in the evolution of host specialization. B. burgdorferi s.1. is maintained in an enzootic cycle between generalist ticks of the Ixodes ricinus complex and reservoir hosts, including small and medium-sized mammals, birds, and reptiles (3-5). Despite being transmitted by the same generalist vector, some B. burgdorferi s.l. genospecies in Europe are almost exclusively associated with a host taxa (e.g. B. afzelii in rodents; $B$. garinii in avian hosts). In contrast, $B$. burgdorferi sensu stricto (hereafter $B$. burgdorferi) in North America is considered a host generalist as it has been isolated from multiple classes of vertebrate animals including mammalian and avian hosts $(3,6-8)$. However, laboratory infection studies indicate that the fitness of B. burgdorferi strains varies in different hosts $(9,10)$. 
In natural populations, weak associations were also found between hosts and particular $B$. burgdorferi genotypes, defined by polymorphic markers, such as ospC or $16 \mathrm{~S}-23 \mathrm{~S}$ rRNA intergenic spacer type (RST) (11-13). An intriguing possibility is that the partially and regionally constrained host associations observed in B. burgdorferi genotypes represent an incipient evolutionary process of host specialization $(4,12,14-17)$. That is, B. burgdorferi may be on an evolutionary path to diversify into host specialized genospecies, similar to those within the $B$. burgdorferi s.l. species complex in Europe. Nonetheless, the molecular processes underlying such diversification and the extent to which they might drive genome-wide diversification in $B$. burgdorferi remain under debate.

Multiple-niche polymorphism (MNP), or diversifying selection, has been proposed as a balancing selection mechanism maintaining the diversity of B. burgdorferi genotypes through adaptation to host 'niches' $(11,12,18,19)$. This model was applied to the maintenance of the polymorphism in the outer surface protein $\mathrm{C}(\mathrm{OspC})$, one of the most diverse Lyme borreliae antigens that is heavily targeted by the vertebrate immune system (20-22). Alternatively (or concurrently), the OspC polymorphism could be maintained in a host-independent manner, through negative frequency-dependent selection. In this form of balancing selection, rare $B$. burgdorferi OspC genotypes to which few hosts have been exposed would have a selective advantage over the more common genotypes to which many hosts have mounted an adaptive immune response; thus maintaining diversity in the population $(14,17,23-25)$. Theoretical studies have examined patterns of OspC diversity predicted by the different proposed eco-evolutionary mechanisms in different ecological settings (25-28), but a mechanistic understanding of the cellular and immunological mechanisms mediating strain-host interactions is critical to disentangle the multiple co-occurring selective pressures. 
In this study, we simultaneously assessed cellular and immunological mechanisms that mediate strain-host interactions using three $B$. burgdorferi strains with variable $\operatorname{ssp} C$ genotypes, as well as the North American rodent and avian reservoir hosts, American robins (hereafter robins) and white-footed mice (Peromyscus leucopus), respectively. We aimed to determine which cellular and immunological mechanisms mediate fitness variation in strain-host species pairs. Specifically, we identified genotypic differences across $B$. burgdorferi interacting with hosts in (1) the role of larval ticks. By characterizing these mechanisms, we aimed to identify plausible selective pressures that shape the composition of B. burgdorferi strain community, its diversity, and population dynamics.

\section{RESULTS}

Borrelia burgdorferi B31-5A4, 297, and cN40 differed in their adhesiveness to fibroblasts, ex compare the capability of genotypically distinct B. burgdorferi to initiate infection in reservoir

137 (Table S1) and displaying similar growth rates in vitro (Fig. S1) were used in this study. Bacterial was intradermally introduced into robins and white-footed mice. We did not detect any of these strains in robin blood (Fig. S2A), in agreement with no hematogenous dissemination at such an early time point (29). However, we found that B31-5A4 and cN40 showed significantly higher 
injection sites from only two out of four 297-inoculated robins had spirochete burdens higher than detection limits (10 bacteria per 100ng of DNA from tissues), leading to non-significant differences in the levels of colonization from mock-infected robins (Fig. 1A). In white-footed mice infections, we did not observe spirochete burdens higher than detection limits of any of these strains in the blood of white-footed mice (Fig. S2B). Nonetheless, the burdens of B31-5A4 and 297 were significantly higher than those from mock-infected individuals at the inoculation site $\left(\sim 10^{2}\right.$ bacteria per $100 \mathrm{ng}$ of DNA). Only two of five white-footed mice had cN40 bacterial loads greater than the detectable threshold limit, resulting in non-significant differences in burdens from mock-infected mice (Fig. 1B). These findings indicate B31-5A4, 297, and cN40 have the capacity to establish infection selectively in robins and white-footed mice.

As the burdens of $B$. burgdorferi during infection initiation can be attributed to differences in spirochete attachment to cells or clearance by host inflammatory responses, we incubated B315A4, 297, and $\mathrm{cN} 40$ with fibroblasts isolated from robin or white-footed mouse for $1 \mathrm{~h}$ and determined the levels of bacterial attachment using fluorescent microscopy (Fig. S3). A nonadhesive B. burgdorferi strain B314 was also included as control (Table S1). Compared to B314, we found that B31-5A4, 297, and cN40 more efficiently bind to the fibroblasts from robins (Fig. 1C) or white-footed mice (Fig. 1D). Whereas B31-5A4 and cN40 bound to robin fibroblasts at significantly higher levels compared to 297 (Fig. 1C), B31-5A4 and 297 attached to white-footed mouse fibroblasts at significantly greater levels compared to cN40 (Fig. 1D). To determine whether B31-5A4, 297, and cN40 trigger differential pro-inflammatory responses in fibroblasts from different reservoir origins, we measured the expression levels of the genes encoding proinflammatory cytokines, IFN $\gamma$ and TNF, or the proteins related to these cytokines after incubating cells with each of the spirochete strains for $24 \mathrm{~h}$. The expression levels of housekeeping genes (18S 
rRNA and $\beta$-actin) were also included as controls. We found that the levels of expression for each of the genes in any spirochete-treated cells were not significantly different from the mock-treated cells at 1 to 10 of the spirochetes to cell ratio (Fig. S4). At 1 to 100 of spirochete to cell ratio, the B31-5A4- or cN40-treated robin fibroblasts expressed similar levels of the tested cytokines to the cells under mock treatment while 297-incubated cells had significantly greater expression of IFN $\gamma$ and TNF-induced protein than mock-treated cells, respectively (Fig. 1F and G). Conversely, while white-footed mouse fibroblasts incubated with B31-5A4 or 297 expressed those cytokines indistinguishably from mock-treated cells, cN40-treated cells showed significantly higher expression of IFN $\gamma$ and TNF (4.6- and 30.1-fold, respectively) than the cells under mock treatment (Fig. 1I and J). These results suggest that B. burgdorferi B31-5A4, 297, and cN40 differ in their fibroblast adhesiveness and cytokine induction in a host-dependent fashion.

\section{Ticks acquired different levels of $B$. burgdorferi B31-5A4, 297, and cN40 from robins and} white-footed mice infected with each of these spirochete strains. To compare reservoir host competence to B31-5A4, 297, and cN40, we assessed spirochete transmission from host to feeding larvae. Unfed I. scapularis nymphs were allowed to feed on robins or white-footed mice until repletion. We subsequently measured bacterial loads in flat and fed nymphs and found indistinguishable burdens among these ticks $\left(\sim 10^{4}\right.$ bacteria per nymph), indicating no differences of the ability for any tested strain to survive in flat or fed nymphs (Fig. S5).

We then placed I. scapularis larvae on robins or white-footed mice at different time points (Fig. 2A) to determine spirochete burdens in each larva and the percentage of spirochete-positive larvae per individual host (defined as percent positivity). The spirochete burdens in uninfected (control) robin-derived larvae were below the detection limit (10 bacteria per tick), resulting in zero 
spirochete positivity at 14, 28, 35, and 56 days post nymph feeding (dpf) (Fig. 2B to F and Table 1). At least $18 \%$ of larvae feeding on B31-5A4-, 297-, or cN40-infected robins were spirochete positive at all time points with greater than detection limits of bacterial loads, indicating the ability of robins to persistently maintain and transmit these strains (Fig. 2C to F and Table 1). The percent positivity of fed larvae carrying cN40 was significantly higher than those harboring 297 at all four time points and significantly greater than those carrying B31-5A4 at 28, 35, and 56 dpf (Fig. 2B and Table 1). Moreover, the cN40-infected larvae had significantly higher bacterial loads than the 297-infected larvae at all time points and significantly greater than those in B31-5A4-infected larvae at 28, 35, and 56dpf (Fig. 2C to F). These data suggest that the cN40 is maintained and transmitted more efficiently in robins than B31-5A4 and 297.

Similarly, we found bacterial burdens lower than detection limits in the larvae feeding on uninfected (control) mice, resulting in zero spirochete positivity (Fig. 2G to K, Table 1). At least 9\% of the larvae feeding on B31-5A4-, 297-, or cN40-infected mice were positive throughout the experiment (Fig. 2G and Table 1). The bacterial loads from those mice were also statistically different from those derived from uninfected mice (Fig. $2 \mathrm{H}$ to $\mathrm{K}$ ), except that larvae infected with cN40 had similar spirochete burdens to uninfected mouse-derived larvae at 56dpi. These data indicate the ability of white-footed mice to maintain and transmit each of these strains. We found significantly lower spirochete positivity in larvae infected with 297 , compared to that in larvae infected with B31-5A4 at 28 and 35 dpf, respectively (p<0.05, Fig. 2G, I, J and Table 1). Finally, larvae infected with $\mathrm{cN} 40$ showed more than significantly lower spirochete positivity (Fig. 2G and Table 1) and had significantly less bacterial burdens than B31-5A4- and 297-infected ticks throughout the experiments (Fig. $2 \mathrm{H}$ to K). These data suggest less capability of white-footed mice to maintain and transmit cN40 compared to B31-5A4 or 297. 
Borrelia burgdorferi B31-5A4, 297, and cN40 varied in their capability to trigger bacteremia were no statistically different from those in uninfected mice (Fig. 3E and H). At 7 and 14 dpf, B31- 
cN40 is less capable of surviving in the white-footed mouse bloodstream compared to B31-5A4 and 297, in contrast to the results derived from robins.

We also evaluated the ability of B31-5A4, 297, and cN40 to colonize robin and white-footed mouse tissues at 64dpf (Fig. 2A). Robins infected with each of these strains had significantly greater spirochete burdens in skin than uninfected robins, which exhibited bacterial loads below the detection limits (Fig. 3I). In addition, spirochetes were detected at significantly greater burdens in the heart and brain of $\mathrm{cN} 40$-infected robins and the heart of robins infected with B31-5A4, compared to respective tissues from uninfected robins (Fig. 3J and K). Majority of the 297- or cN40-infected robins ( 3 out of 4 and 3 out of 5 in 297- and cN40-infected robins, respectively) had burdens below the detection limits in livers, yielding no significantly different burdens from those in uninfected robins (Fig. 3L). Similarly, the burdens of B31-5A4 in the livers from spirochete-infected robins were no significantly different from those from uninfected robins (Fig. 3L). These data showed persistent skin colonization of strains B31-5A4, 297, and $\mathrm{cN} 40$ in robin, but the ability of each strain to colonize other tissues varied (Fig. 3I to L). We also measured the bacterial burdens at $64 \mathrm{dpf}$ in the tissues from white-footed mice infected with each of these strains. We detected spirochetes in ears, tibiofemoral joints, heart, and bladder from mice infected with B31-5A4 or 297 ( $\sim 10^{2}$ to $10^{3}$ bacteria per 100ng of DNA from tissues). The bacterial burdens in tibiofemoral joints, heart, and bladder from B31-5A4- or 297- but not cN40-infected mice were significantly greater than those in uninfected mice (Fig. 3M to P). These findings demonstrated the ability of B31-5A4 and 297 but not $\mathrm{cN} 40$ to persistently colonize white-footed mice.

\section{Robin but not white-footed mouse complement differentiated the ability of $B$. burgdorferi}

B31-5A4, 297, and cN40 to survive in sera. To define the capability of B31-5A4, 297, and cN40 
to evade complement-mediated killing, we evaluated the percent survival after incubation of these strains individually with the sera from uninfected robins or white-footed mice by counting the number of motile bacteria under microscopes. More than $95 \%$ of all tested strains including a serum sensitive control strain, B. burgdorferi B313 (30), survived in heat inactivated robin sera, in which the heat sensitive components such as complement were not functional (Fig. 4A and Table S1). Less than $16 \%$ of B313 remained motile, verifying the bactericidal activity of these robin sera (Fig. 4A). More than $85 \%$ of B31-5A4 and cN40 were alive, but only $50 \%$ of 297 was motile after incubated with robin sera (Fig. 4A). However, all strains survived at similar levels (greater than $80 \%$ of live spirochetes) in the sera pre-treated with OmCI, which inactivates robin complement by abolishing the lytic activity towards gram negative bacteria (Fig. 4B) (31). These results indicate that the 297 is more vulnerable to robin complement-mediated killing than B315A4 and cN40. We also determined the ability of spirochete strains to evade killing by whitefooted mouse complement in the similar fashion. Greater than 95\% of B313, B31-5A4, 297, and cN40 survived in heat inactivated white-footed mouse sera (Fig. 4C). Whereas only 29\% of B313 remained motile after treated with these sera, more than $97 \%$ of other tested strains were alive in the untreated white-footed mouse sera (Fig. 4C). More than 93\% of tested strains remained motile in white-footed mouse sera treated with CVF, which inactivates mammal complement (Fig. 4D) (32). These results indicate that all tested strains evade the killing by white-footed mouse complement at indistinguishable levels.

\section{Robins and white-footed mice generated different levels of pro-inflammatory cytokines in} response to early infection of $B$. burgdorferi B31-5A4, 297, and cN40. We compared the levels of pro-inflammatory cytokines, IFN $\gamma$ and $\mathrm{TNF} \alpha$, in the sera derived from robin- and white-footed 
mice at different times during the infection. We found no significant different levels of IFN $\gamma$ and $\mathrm{TNF} \alpha$ in robins prior to the infection among different infection groups (Fig. 5A and E). At 7dpf, B31-5A4- or cN40-infected robins were not significantly different in those cytokines compared to uninfected robins, 297-infected robins produced significantly greater levels of IFN $\gamma$ and TNF $\alpha$ than those uninfected birds, respectively (Fig. 5B and F). At 14dpf, the levels of these cytokines from those robins are no different from those in uninfected robins. In contrast to robins at $7 \mathrm{dpf}$, cN40-infected mice displayed significantly higher levels of these cytokines than uninfected mice at this time point while 297-infected mice had no significantly different in the levels of those cytokines, compared to uninfected mice (Fig. 5J and N). Note that B31-5A4-infected mice had significantly greater levels of IFN $\gamma$ (Fig. 5J) but were not significantly different from levels of TNF $\alpha$ at $7 \mathrm{dpf}$ (Fig. 5N), compared to uninfected mice. These data indicate differences of proinflammatory cytokine induction by each of these spirochete strains, particularly at early stages of robin and white-footed mouse infection.

\section{Robins and white-footed mice developed distinct levels of bactericidal antibodies during} early infection of $B$. burgdorferi B31-5A4, 297, or cN40. We aimed to quantitatively measure the levels of antibodies induced by the infection of B31-5A4, 297, and cN40. To avoid the confounding factors of strain-specific antibody recognition observed previously $(10,33)$, we mixed these strains and determined the IgG titers against such mixtures in robins infected with B31-5A4, 297, or cN40. We found that robins infected with any strain develop significantly higher anti-spirochete IgG titers than uninfected robins at 14, 21, and 28dpf whereas only 297-infected robins had significantly higher tiers of IgG than uninfected robins at $7 \mathrm{dpf}$ (Fig. 6B to E). cN40 triggered significantly greater levels of IgG antibodies compared to the other strains at 21 and 28 
dpf whereas 297 induced IgG titers significantly higher than those titers triggered by other strains at $7 \mathrm{dpf}$ (Fig. 6B, D and E). Further, we found that white-footed mice infected with each of these strains had anti-spirochete IgG titers at more robust levels than uninfected mice at 14,21 , and 28dpf whereas only cN40-infected mice developed significantly higher tiers of IgG than uninfected white-footed mice at 7dpf (Fig. 6G to J). cN40 induced significantly lower titers of such IgG at 21 and 28dpf but significantly higher titers at 7dpf, compared to B31-5A4 and 297 (Fig. 6G, I and J). These results indicate that B31-5A4, 297, and cN40 differ in their ability to induce antibodies, and such differences depend on the hosts and infection onset. negatively corresponded to the ability of these hosts to carry spirochetes (Fig. 2B and G). This

313 finding raised a hypothesis that such correspondences are mediated by bactericidal activities of 314 those antibodies. We thus tested this hypothesis by incubating a mixture of B31-5A4, 297, and 315 cN40 with different dilution rates of sera from robins or white-footed mice infected with each of these strains at 7dpf. We found that B31-5A4- and cN40-derived robin sera did not kill spirochetes

317 at any of the tested dilution rates, similar to sera from uninfected robins. However, 297-derived sera eliminated $50 \%$ of spirochetes at the dilution rate of 1:52× (Fig. 6K). Conversely, B31-5A4and 297-derived white-footed mouse sera did not eliminate spirochetes, similar to the sera from uninfected mice. However, cN40-derived sera eliminated $50 \%$ of spirochetes at the dilution rate of $1: 32 \times$ (Fig. 6L). These finding showed different levels of bactericidal activities from the antibodies produced by B31-5A4-, 297-, or cN40-infected robins and white-footed mice early during infection.

\section{DISCUSSION}


Theory predicts that generalist vectors should select for generalist pathogens, to minimize the latter's loss to incompetent hosts. Host-specialized genospecies in B. burgdorferi s.l. thus represent a paradox, with the intriguing possibility of incipient host specialization within genotypes of the generalist $B$. burgdorferi. We present evidence of molecular mechanisms that differentially influence the ability of three strains of B. burgdorferi to colonize, disseminate to distal tissues, evade host immune responses, and be transmitted from the host to feeding ticks between two representative natural reservoir hosts (Fig. 7). We found that cellular and immunological mechanisms act mostly synergistically, resulting in increased fitness of strain $\mathrm{cN} 40$ in robins and 297 in white-footed mice. Contrary to theoretical expectations, strain B31-5A4 was able to efficiently infect both hosts, with higher fitness in white-footed mice than the 'specialized' strain, 297, and exhibited intermediate fitness in robins. The synergistic nature of those cellular and immunological mechanisms indicates a strong selective pressure for the evolution of host specialization, as predicted by the MNP theory. However, the higher overall fitness of B31-5A4 does not support the existence of tradeoffs, with this strain having high fitness in both representative hosts. This higher fitness advantage is consistent with the high overall prevalence of the genotype of this strain (RST type 1/OspC type A) circulating in Lyme disease prevalent regions of North America (10, 13, 34-37).

Multiple mechanisms were tested in this study for their role in contributing to host specialization of $B$. burgdorferi. At one day after intradermal infection of spirochetes, we found that $B$. burgdorferi $\mathrm{B} 31-5 \mathrm{~A} 4$ and $\mathrm{cN} 40$ colonized robin inoculation sites (skin tissue) more efficiently than 297, whereas B31-5A4 and 297 colonized the inoculation sites of white-footed mice at significantly higher levels than $\mathrm{cN} 40$. We also found that these strains differed in their capability to attach to robin and white-footed mouse skin fibroblasts in vitro. These results showed that strain- 
to-strain variability of fibroblast adhesion is host-dependent and corresponds to the ability of $B$. burgdorferi spirochetes to colonize the inoculation sites of these hosts immediately after infection. This supports prior findings of Lyme borreliae strains varying in their adhesive activities (38), demonstrating the role of such cellular processes (adhesion) in conferring strain-host associations. However, the levels of robin fibroblast adhesion of B31-5A4, 297, and cN40 did not perfectly agree to strain colonization of other tissues (e.g. brain and liver) in robins at 64 days after being fed on by B. burgdorferi-infected nymphs. Additionally, strain 297 colonized robin skin at similar levels to B31 and cN40 at $64 \mathrm{dpf}$, but this strain attached to robin fibroblast at lower levels than other strains. These disagreements between fibroblast adhesion/early colonization of inoculation sites and tissue colonization at later stages suggest the possibility of adhesion-independent mechanisms to determine strain-host associations. In fact, the complement system is the first line of immune defense in vertebrate animal sera and confers Lyme borreliae clearance as soon as infection begins $(39,40)$. Our findings of greater percentages of B31-5A4 and cN40 surviving in robin sera, compared to those of 297, mirror the trends of these spirochete strains being maintained at earlier infection onsets (e.g. $14 \mathrm{dpf}$ ) and early bloodstream survival of B. burgdorferi (e.g. 7 dpf). These results imply that the host complement plays a role in determining spirochete genotype-specific robin competence. In contrast, all three B. burgdorferi strains showed similar levels of survival in the presence of white-footed mouse sera, suggesting a non-complementmediated defense mechanism to dominate the association of white-footed mice with these spirochetes.

In addition to complement, we compared the cytokine production in responding to the presence of genotypically distinct B. burgdorferi. Cytokines are generally triggered shortly after pathogen invasions, often leading to activation of different pathways and downstream bactericidal responses 
as a bottleneck of infection initiation (i.e. recruitment of innate and adaptive immune cells) (4145). Borrelia burgdorferi strain-to-strain variability in inducing pro-inflammatory cytokines has been observed in humans, Mus musculus, and P. leucopus mice or from cells derived from these animals (46-52). In humans, the levels of multiple cytokines are positively correlated with disease severity but are independent from spirochete burdens $(46,47,53-55)$. We found that the three tested B. burgdorferi strains differed in their ability, in robins and white-footed mouse fibroblasts, to induce the expression of two pro-inflammatory cytokines and their related proteins, IFN $\gamma, \mathrm{TNF} \alpha$, and $\mathrm{TNF} \alpha$-induced proteins. Such differences also matched the variation of these strains to trigger IFN $\gamma$ and TNF $\alpha$ during early infection. The ability of these strains to induce those proinflammatory cytokines were negatively associated with larval percent positivity from the infection of these B. burgdorferi strains. These results raised the hypothesis that less robust host cytokine induction by spirochetes facilitates reservoir competence, and differences in cytokine induction by genotypically distinct spirochetes shape Lyme borreliae-reservoir associations.

Following the induction of innate immune responses, the adaptive responses including antibodies are essential in Lyme borreliae clearance by vertebrates $(41,56,57)$. Distinct levels of antibodies were observed during the infection time period by different spirochete strains $(10,58)$. We observed at $7 \mathrm{dpf}$ that 297 and $\mathrm{cN} 40$ triggered significantly higher titers of anti-B. burgdorfer $i$ IgG in robins and white-footed mice, respectively, compared to the other spirochete strains. Furthermore, B. burgdorferi was selectively eliminated by the sera collected at $7 \mathrm{dpf}$ from robins infected with 297 or white-footed mice infected with $\mathrm{cN} 40$, suggesting that the antibody response varies among different spirochete strain-host pairings. Interestingly, a previous study showed variable IgG levels against lp36- and lp28-1-derived proteins in white-footed mice infected with different B. burgdorferi strains (10). However, in that study, those 1p36- and lp28-1-derived 
proteins were produced from a single strain of B. burgdorferi (B. burgdorferi strain B31), leading to the possibility that allelic-specific recognition is the result of antigenic sequence variation among spirochete strains $(10,33,59-61)$. Thus, the possibility of the antibodies against other spirochete proteins to confer $B$. burgdorferi clearance may not be completely ruled out. Our finding of early antibody-mediated bactericidal activities in robin and white-footed mouse sera highlights the potential role of antibodies in dictating pathogen-host associations. We observed high titers of antibody responses at late time points ( 21 and $28 \mathrm{dpf}$ ) in robins infected with $\mathrm{cN} 40$ and mice infected with B31-5A4- or 297. Nonetheless, cN40 was persistently maintained in robins whereas B31-5A4 and 297 efficiently survived long-term in white-footed mice. Such observations are consistent with the evidence of pathogen-specific antibodies present in persistently infected animals (62-64). These results thus suggest inefficient spirochete elimination by those antibodies at later stages of infection. That inefficient pathogen killing could be because of the onsetdependent reduction of highly antigenic spirochete proteins (i.e. downregulation of $\mathrm{OspC}$ at late infection onsets) (65-69), constantly changing features of antigen sequences to evade antibody responses (i.e. VlsE) (70-72), or the rapid dissemination of spirochetes to the sites less vulnerable to antibody-mediated clearance (73).

Our results suggest spirochete adhesiveness and early immune responses as the cellular and immunological mechanisms that differentially confer spirochete fitness in reservoir-strain-host combinations (Fig. 7). Both mechanisms could play in concert to determine B. burgdorferi strainto-strain variation in host fitness. Our findings support previous studies which determined that some polymorphic Lyme borreliae proteins confer these immune response functions in a variantspecific manner, and such manner is host dependent $(30,59,62,63,74-80)$. The potential for host specialization driving genome-wide diversification is illustrated by the recent definition of a new 
species of $B$. burgdorferi s.l., B. bavariensis, which was previously considered a genotype of the avian associated species, $B$. garinii. Such a redefinition is based on the variation in chromosomal housekeeping genes and the association of this species with rodents, unlike other B. garinii strains (81). This reclassification reflects how host adaptation can lead to speciation in Lyme borreliae (82). Prior field studies along with our current laboratory evidence showing incipient host specialization raises the possibility of diversification of B. burgdorferi in North America into multiple genospecies. Here, we used a controlled laboratory setup to demonstrate differences in specialization even with a significant cost in lost propagules to incompetent hosts. The identified mechanisms can guide future empirical and modeling studies to understand the role of hostpathogen-vector interactions in shaping the microparasite host ranges and their potential for pathogen spillover into livestock, wildlife or humans.

\section{MATERIALS AND METHODS}

Ethics statement. All experiments involving American robins (Turdus migratorius) and white- 
approved on scientific collecting permits USFWS Collecting Permit MB035731 and NYSDEC Permit \#1236.

Bird, Mouse, Tick, and Bacterial strains. From June-July, 2019 and July, 2020, American robins were mist netted around the property of Griffin Laboratory of Wadsworth Center, New York State Department of Health at Albany, NY. This site was selected because of previously reported low tick abundance, thus minimizing the probability of previous tick exposure. Sera were collected from 32 and 17 robins in 2019 and 2020, respectively, using BD Microtainer Capillary Blood Collector tubes (Fisher Scientific, Hampton, NH, USA) to assess previous infection with $B$. burgdorferi infection by the methods previously described (31). To confirm seronegative status, robins were quarantined for two weeks at $25^{\circ} \mathrm{C}$ on a 12L:12D (light: dark) cycle by housing them in cages with a wire bottom, under which a water moat was placed. If replete ticks were found while the birds were in quarantine, quantitative PCR (qPCR) was used to determine the spirochete burdens in those ticks (see "Quantification of B. burgdorferi in infected ticks, tissues, and blood samples" for more details). The birds with spirochete positive ticks attached were removed from the experiments. After two weeks of quarantine, robins were subjected to additional serological examination as described above, and 40 seronegative juvenile (hatch year) robins were considered non-infectious and used in this study.

White-footed mice were purchased from the Peromyscus Genetic Stock Center at the University of South Carolina (Columbia, SC). Non-sibling mice were bred in-house at Columbia University. Immunodeficient Fox Chase SCID mice (C.B.17 SCID) were obtained from Charles River (Boston, MA) and used to generate infected nymphs for each B. burgdorferi strain as described in the "Mouse infection experiments by ticks" section. Ixodes scapularis larvae were purchased from the 
National Tick Research and Education Center, Oklahoma State University (Stillwater, OK). Mice and birds were housed individually and maintained at 21 to $24^{\circ} \mathrm{C}$ on a $14 \mathrm{~L}: 10 \mathrm{D}$ (light: dark) cycle and handled humanely. The B. burgdorferi strains used in this study were cultivated in BSK-II completed medium as described in Table $1(83)$.

Determination of spirochete growth curves and generation time. Borrelia burgdorferi strains B31-5A4, 297, and cN40 were cultivated in BSK-II complete media at $33^{\circ} \mathrm{C}$ in the initial concentration of $5 \times 10^{6} \mathrm{ml}^{-1}$. The concentration of spirochetes was measured prior to incubation and at 24-, 48-, 72-, 96-, 120-, 144-, and 168-h post incubation using a Nikon Eclipse E600 dark field microscope (Nikon, Melville, NY). The generation time of each spirochete strain at the exponential phase was calculated as described previously (84).

\section{Robin, C.B.17 SCID mouse, and white-footed mouse infection by intradermal inoculation.} Four to eight week old male or female white-footed mice, American robins, or C.B.17 SCID mice were intradermally inoculated, using a 27-gauge needle, with B. burgdorferi B31-5A4, 297, cN40, or BSK-II medium without rabbit sera $\left(1 \times 10^{5}\right.$ bacteria per C.B.17 SCID mouse or $1 \times 10^{4}$ bacteria per robin or white-footed mouse) as a control (63). The plasmid profiles and the presence of the shuttle plasmids of each of these B. burgdorferi strains were verified prior to infection to ensure no loss of plasmids, as described previously (85-87). Both robins and white-footed mice were euthanized at one day post injection. The inoculation site of the skin and blood from robins and white-footed mice were collected to quantitatively evaluate spirochete burdens as described in the "Quantification of B. burgdorferi in infected ticks, tissues and blood samples" section. 
Quantification of $B$. burgdorferi in infected ticks, tissues, and blood samples. The white-footed mouse- or robin-derived replete nymphs were mixed with glass beads and homogenized by a from blood and tissue samples of white-footed mice, robins and homogenized ticks using an EZ10 Genomic DNA kit (Biobasic, Amherst, NY). The quantity and quality of DNA for each tissue sample was assessed by measuring the concentration of DNA and the ratio of the UV absorption at 280 to 260 using a nanodrop $1000 \mathrm{UV} / \mathrm{Vis}$ spectrophotometer (ThermoFisher Scientific, Waltham, MA). The amount of DNA used in this study was $100 \mathrm{ng}$ for each sample, and the 280:260 ratio was between 1.75 to 1.85 , indicating the lack of contamination by RNA or proteins. qPCR was performed to quantitate bacterial loads. Borrelia burgdorferi genomic equivalents were calculated using an Applied Biosystems 7500 Real-Time PCR system (ThermoFisher Scientific) in conjunction with PowerUp SYBR Green Master Mix (ThermoFisher Scientific), based on amplification of the B. burgdorferi $16 S$ rRNA gene using primers 16S rRNAfp and 16S rRNArp (Table S2), as described previously (88). Cycling parameters for SYBR green-based reactions were $50^{\circ} \mathrm{C}$ for $2 \mathrm{~min}, 95^{\circ} \mathrm{C}$ for $10 \mathrm{~min}, 45$ cycles of $95^{\circ} \mathrm{C}$ for $15 \mathrm{~s}$, and $60^{\circ} \mathrm{C}$ for $1 \mathrm{~min}$. The number of $16 \mathrm{~S} r R N A$ copies was calculated by establishing a threshold cycle $(\mathrm{Ct})$ standard curve of a known number of $16 S r R N A$ gene copies extracted from B. burgdorferi strain B31, and compared to the $\mathrm{Ct}$ values of the experimental samples. To ensure low signals were not simply a function of the presence of PCR inhibitors in the DNA preparation, five samples of blood, tibiofemoral joints, bladders of white-footed mice and the skin, brain, and heart of robins in the B31-5A4 experimental group were applied to qPCR to determine the levels of $\beta$-actin from white-footed mice (pActfp and pActrp) and robins (rActfp and rActrp), respectively (Table S2) $(63,89)$. Note that the primers 
sequences that were translated to protein (Genbank Accession number: PYHW01009720.1) from a closely related avian host, rufous-bellied thrush (Turdus rufiventris) due to the lack of sequence information of American robin actin. As predicted, we detected $10^{7}$ copies of the actin gene from 100ng of each DNA sample in robins and white-footed mice, ruling out the presence of PCR inhibitors in these samples.

Isolation of robin fibroblasts. The procedures to isolate robin fibroblasts were described previously (90). Five $5 \mathrm{~mm} \times 5 \mathrm{~mm}$ sections of skin were removed from the breast of euthanized robins, washed twice in PBS buffer, and then incubated in a transferring solution until the next step was ready to be performed. The constituents of the transferring solution included Dulbecco's modified Eagle medium (DMEM) (Wadsworth media \& tissue culture core) with glucose (4.5mg $\mathrm{ml}^{-1}$ ) (Sigma-Aldrich, St. Louis, MO), sodium pyruvate (110 $\mathrm{mg} \mathrm{1}^{-1}$ ) (Sigma-Aldrich), L-glutamine (ThermoFisher Scientific), supplemented with 10\% heat-inactivated fetal bovine serum (ThermoFisher Scientific), 2\% heat-inactivated chicken serum (Biowest, Riverside, MO, USA), and antibiotics (100U ml $\mathrm{U}^{-1}$ of mixture of penicillin and streptomycin) (ThermoFisher Scientific). The skin was then submerged in $70 \%$ ethanol (Sigma-Aldrich) for 30s, minced using sterile scalpels, and placed in collagenase $\mathrm{B}$ at $37^{\circ} \mathrm{C}$ overnight (ThermoFisher Scientific). We then applied the mixture of the cells to a $20 \mu \mathrm{m}$ cell strainer and spun down the samples. The pellets containing fibroblasts were re-suspended in growth media and incubated at $37^{\circ} \mathrm{C}$ with $5 \% \mathrm{CO}_{2}$. Growth media had the same components as the transferring solution except it was supplemented with amphotericin B (ThermoFisher Scientific) to a concentration of $0.25 \mu \mathrm{g} / \mathrm{ml}$. The cells were harvested by trypsinization using Trypsin (0.25\% trypsin in DMEM media, ThermoFisher Scientific) and used in the spirochete attachment experiment. 
Determination of the levels of spirochete attachment to robin and white-footed mouse

fibroblasts. The primary fibroblasts from the neck skin of American robins (see the previous section) and ears of white-footed mice were acquired commercially (\#AG22353, Coriell Institute per well). Borrelia burgdorferi strains B31-5A4, 297, cN40, or B314 were suspended in BSK-II medium and added to prepared plates $\left(2 \times 10^{6}\right.$ spirochetes per well $)$. The plates were centrifuged at $106 \mathrm{~g}$ for $5 \mathrm{~min}$ and then rocked at room temperature for $1 \mathrm{~h}$. After removing unbound bacteria through washing each well with PBS containing $0.2 \%$ BSA, the bound bacteria and cells on the cover slips were fixed using $100 \%$ chilled methanol for $1 \mathrm{~h}$ followed by blocking with PBS containing $0.2 \%$ BSA for $1 \mathrm{~h}$. After washing with PBS containing $0.2 \% \mathrm{BSA}$, the cover slips were incubated with a fluorescein isothiocyanate (FITC)-conjugated goat anti-B. burgdorferi polyclonal antibody (Abcam, Cambridge, MA) for $1 \mathrm{~h}$ and mounted using ProLong Gold antifade mountant spirochetes and the nuclei of fibroblasts (blue) were then visualized under overlaid FITC and DAPI events. The results were presented as the average number of spirochetes per 50 fibroblast cells. 
556 footed mice were cultivated in 24 -well plates $\left(2 \times 10^{5}\right.$ cell per well). When the cells were greater than $80 \%$ confluent, B. burgdorferi strains B31-5A4, 297, or cN40 suspended in BSK-II medium were added to corresponding wells on each plate $\left(2 \times 10^{6}\right.$ and $2 \times 10^{7}$ spirochetes per well for the cell to spirochete ratio (MOI) of 1:10 and 1:100, respectively) for $24 \mathrm{~h}$. The cells incubated with BSK-II medium without bacteria (mock-treated cells) were included as a control.

After incubation, the supernatant was removed, and the cells were washed with PBS buffer. These fibroblasts were then suspended in Trizol (ThermoFisher Scientific) at room temperature for $1 \mathrm{~h}$ to inactivate RNase. The procedure of RNA extraction was performed using Direct-Zol RNA MiniPrep Plus Kit (Zymo Research, Irvine, CA) as previously described (84), and DNA was removed using RQ1 RNase-Free DNase (Promega, Madison, WI). We then synthesized cDNA using these RNA samples ( $1 \mu \mathrm{g}$ per sample) by qScript cDNA SuperMix (Quanta Bioscience, Beverly, MA). The expression levels of the house keeping genes encoding the 18S rRNA gene from robins (Genbank Accession number: M59402.1) or white-footed mice (Genbank Accession number: AY591913.1) were included as controls. The primers used to quantitate the expression of the genes encoding white-footed mouse IFN $\gamma, \mathrm{TNF}$, and $18 \mathrm{~S}$ rRNA, and robin IFN $\gamma$, TNF $\alpha$ induced proteins, and 18S rRNA are listed in Table S2 (89). Note, because of the lack of sequence

572 information for robin cytokines, the primers to determine the expression of these cytokines were based on the mRNA sequences of IFN $\gamma$ (Genbank Accession number: PYHW01010552.1) and TNFa-induced proteins (Genbank Accession number: PYHW01009717.1) from rufous-bellied

575 thrush (Turdus rufiventris). The quantity and quality of cDNA for each sample was evaluated by 576 obtaining the concentration of DNA and the ratio of the UV absorption at 260 and 280 using a 577 Nanodrop $1000 \mathrm{UV} /$ Vis spectrophotometer (ThermoFisher, Waltham, MA). The resulting ratio between 1.75 and 1.85, indicated the lack of RNA or protein contamination. Samples were applied 
579 to an Applied Biosystems 7500 Real-Time PCR System (ThermoFisher) in conjunction with

580 PowerUp SYBR Green Master Mix (ThermoFisher) to detect the expression levels of the above-

581 mentioned genes. The cycling parameters were $50^{\circ} \mathrm{C}$ for $2 \mathrm{~min}, 95^{\circ} \mathrm{C}$ for $10 \mathrm{~min}$, and 45 cycles of

$58295^{\circ} \mathrm{C}$ for $15 \mathrm{~s}$, and $49^{\circ} \mathrm{C}$ for $1 \mathrm{~min}$, and the resulting values of threshold cycles $(\mathrm{Ct})$ were

583 determined from duplicate experiments in three independent events. The relative expression of the

584 genes encoding IFN $\gamma, \mathrm{TNF}, \mathrm{TNF} \alpha$-induced proteins, or $18 \mathrm{~S}$ rRNA was presented by normalizing

585 the Ct-derived from each of these cytokines to that of $\beta$-actin from respective animals through the

586 following equation (Equation 1).

cytokine expression relative to actin $=2^{-(\text {Ct(cytokines })-C t(\text { actin }))}($ Equation 1$)$

Generation of B. burgdorferi-infected nymphal ticks. Four-week-old male and female C.B.17

SCID mice were injected with a concentration of $1 \times 10^{5}$ of either B. burgdorferi strain B31-5A4,

297, or cN40 via subcutaneous injection. The plasmid profiles and the presence of the shuttle 
$21^{\circ} \mathrm{C}, 95 \%$ relative humidity, and a $14 \mathrm{~L}: 10 \mathrm{D}$ light: dark cycle. Larvae molted into the nymphal life stage in approximately 4-6 weeks and were used in the subsequent experiments with whitefooted mice and robins.

Robin and white-footed mouse infection by nymphs. The timeline of experimental procedures is provided in Fig. 2A. Basically, unfed nymphs carrying B31-5A4, 297, cN40 or unfed, uninfected nymphs were placed in the ear canals of each mouse ( $n=5$ mice per group, 5 nymphs in each ear). Mice were maintained under anesthesia for $60 \mathrm{~min}$ to allow nymphs to attach before being placed individually in water bath cages. Approximately 100 to 150 xenodiagnostic larvae were placed on each mouse at $14,28,35$, and 56 days post nymph feeding using the aforementioned procedure. To permit flat nymphs to feed on robins, the birds were placed into a PVC pipe $(\sim 2.5-3.0$ inches in diameter; 10 inches in length) as described (92). After unfed nymphs carrying B31-5A4, 297, $\mathrm{cN} 40$ or unfed, uninfected nymphs were placed on these robins $(n=5$ robins per group, 10 nymphs per bird), the PVC pipes were covered by a fine mosquito net ('no-see-um' netting, Skeeta, Bradenton, FL) secured with a rubber band. The birds were then moved into wire bottom cages with a water moat. These tick-infested robins were kept in a dark room for $1 \mathrm{~h}$ to minimize grooming and allow ticks to attach before they were released and returned to their cages. To allow xenodiagnostic larvae to feed on robins, approximately 100 to 200 naïve larvae were placed on robins restrained in the PVC pipes as described above at 14, 28, 35, and 56 days post nymph feeding.

Blood samples were collected from each animal (robins and white-footed mice) prior to nymph feeding and at $7,14,21$, and 28 days post nymph feeding. The skin, heart, liver, and brain from robins and the ears, tibiofemoral joints, heart, and bladder from white-footed mice were obtained 
at 64 days post nymphs feeding. The blood, tissues, and replete nymphs collected from each animal were analyzed via $\mathrm{qPCR}$ to determine spirochete burdens as described in the section "Quantification of B. burgdorferi in infected ticks, tissues, and blood samples".

Serum resistance assays. Serum resistance of B. burgdorferi strains was determined as described previously with modifications $(30,84)$. The mid-log phase of B. burgdorferi strains B31-5A4, 297, and $\mathrm{cN} 40$ as well as a high passage, serum sensitive strain B313 (negative control) were cultivated in triplicate. The resulting spirochete culture was diluted to a final concentration of $5 \times 10^{6}$ bacteria per milliliter into BSK-II medium without rabbit sera. The cell suspensions were mixed with sera collected from naïve white-footed mice or robins (60\% spirochetes and $40 \%$ sera) in the presence or absence of $2 \mu \mathrm{M}$ of cobra venom factor (CVF) or recombinant Ornithordorus moubata complement inhibitor (OmCI). The generation of recombinant OmCI has been described previously (31). The sera were incubated at $65^{\circ} \mathrm{C}$ for $2 \mathrm{~h}$ (heat-inactivated sera) and included as a control. At 0 and $4 \mathrm{~h}$ following incubation with sera, the number of motile spirochetes was measured under dark field microscopy. The percent survival of B. burgdorferi was calculated by the normalization of motile spirochetes at $4 \mathrm{~h}$ post incubation to that immediately after incubation with sera.

Determination of the relative levels of IFN $\gamma$ and TNF $\alpha$ in sera by ELISA. Due to the lack of commercially available ELISA kits to detect robin cytokines, the kits for chicken IFN $\gamma$ (ThermoFisher) and TNFa (Genorise, Glen Mills, PA) were used to measure the levels of those cytokines in robins based on the absorption values derived from ELISA. Similarly, the ELISA kits to determine the levels of IFN $\gamma$ and TNF $\alpha$ from house mouse (Mus muscuslus) (Tonbo Bioscience, 
San Diego, CA) were utilized to detect those cytokines in white-footed mice. We observed the antibodies in the ELISA kits cross reacted with IFN $\gamma$ and TNF $\alpha$ from robins and white-footed mice. However, the recombinant proteins provided in these kits to generate standard curves were based on the sequences from chicken and house mouse IFN $\gamma$ and TNF $\alpha$, potentially leading to inaccuracy of quantification for those cytokines by normalizing the results obtained from robin and whitefooted mouse samples to standard curves. Therefore, we chose to present reservoir animal cytokines as relative levels (arbitrary unit; A.U.), similar to a previous study (93). In brief, the monoclonal capture antibodies that recognized chicken or house mouse IFN $\gamma$ or TNF $\alpha$ were coated on microtiter plate wells. After blocked by 5\% PBS-BSA, different dilutions $(1: 100 \times, 1: 300 \times$, or $1: 900 \times)$ of sera from robins and white-footed mice at $0,7,14$, or 21 days post nymph feeding were added to the wells. Wells were washed using PBST buffer (PBS with 0.5\% of Tween 20) and the detection of antibodies against chicken or house mouse IFN $\gamma$ or TNF $\alpha$ were incubated for $1 \mathrm{~h}$ at room temperature. The wells were then washed with PBST buffer and subsequently mixed with a tetramethyl benzidine solution (ThermoFisher). The absorbance level was detected at $620 \mathrm{~nm}$ for 10 cycles of $60 \mathrm{~s}$ kinetic intervals with $10 \mathrm{~s}$ of shaking duration in a Sunrise absorbance ELISA plate reader (Tecan, Männedorf, Switzerland). We then obtained the greatest maximum slope of optical density/min per sample multiplied by respective serum dilution factors to represent the relative levels of cytokines shown as arbitrary units.

\section{Determination of the titers of the antibodies against spirochetes. The titers of IgG against} spirochetes were measured as described previously with modifications (94). Basically, microtiter plate wells were coated with a mixture of B. burgdorferi B31, 297, and cN40 $\left(1 \times 10^{6}\right.$ spirochetes per strain in a well). After blocking with 5\% PBS-BSA, the sera from white-footed mice or robins 
671 collected at $7,14,21,28$, and 56 days post nymph feeding were diluted in $50 \mu 1$ of PBS $(1: 100 \times$,

$6721: 300 \times$, or 1:900×) and then added to the wells. After the samples were washed with PBST buffer,

673 the microtiter wells were incubated with antibodies that recognize the Fc region of $\operatorname{IgG}$ from $P$.

674 leucopus $(1: 1,000 \times$, Serocare, Inc, Milford, MA), or wild bird $(1: 10,000 \times$, Bethyl laboratory,

675 Montgomery, TX). After the addition of these antibodies, tetramethyl benzidine solution

676 (ThermoFisher) was added, and the absorbance was detected at $620 \mathrm{~nm}$ for 10 cycles of $60 \mathrm{~s}$ kinetic

677 intervals with $10 \mathrm{~s}$ of shaking duration in a Sunrise absorbance ELISA plate reader (Tecan,

678 Männedorf, Switzerland). The values of greatest maximum slopes of optical density/min/sample

679 were multiplied by respective serum dilution factors as shown as arbitrary units, representing

680 antibody titers.

681

682

Borreliacidal assays. Sera collected from robins and white-footed mice at 7 days post tick feeding were used to measure the bactericidal activity against B. burgdorferi as described previously (95).

The complement in these serum samples was heat-inactivated by incubating these samples at $55^{\circ} \mathrm{C}$

for $2 \mathrm{~h}$. The heat inactivated sera were serially diluted in BSK-II media without rabbit sera

686

687

688

689

690

691

692

693

followed by being mixed with complement-preserved sera from guinea pig (Sigma-Aldrich) or chicken (Biowest, Riverside). Heat-inactivated guinea pig and chicken sera were included as controls. Borrelia burgdorferi strains B31-5A4, 297, or $\mathrm{cN} 40\left(1 \times 10^{7}\right.$ spirochetes per strain $)$ were then mixed prior to their addition to the reaction. At $24 \mathrm{~h}$ after incubation, the surviving spirochetes were quantified by counting the motile bacteria under dark-field microscopy and presented as the proportion of serum-treated to untreated spirochetes. We also calculated the $50 \%$ borreliacidal titer (BA), which represents the serum dilution rate that eradicates $50 \%$ of spirochetes, using doseresponse stimulation fitting in GraphPad Prism 7. 
Statistical analyses. Because the data were not normally distributed, we used a Kruskal-Wallis test followed by a two-stage step-up method with a Benjamini, Krieger, and Yekutieli correction for all comparisons (96). Geometric means of duplicated individual samples (qPCR) were used in cN40) and uninfected samples in robins, white-footed mice, or ticks were compared using normalized qPCR quantity values for each individual. Cell adhesion variation among the $B$. burgdorferi strains were analyzed using the number of spirochetes per 50 fibroblast cells observed under fluorescent microscopy while the variation in expression levels of the genes encoding IFN$\gamma, \mathrm{TNF}$, or TNF $\alpha$-induced protein were first normalized by the gene encoding actin and then

704 significant differences between the constitutively expressed gene, actin, and 18S rRNA were determined using RT-qPCR quantity values. However, when comparing the differences between levels of pro-inflammatory cytokines at early stages of host infection, we used quantitative ELISA values. Spirochete survival in treated and untreated host sera was assessed using the number of mobile spirochetes at $4 \mathrm{~h}$ post incubation. We used quantitative ELISA values to determine the significant differences among the B. burgdorferi strains and levels of IgG antibody production in robins and white-footed mice. All analyses and figure generation were completed using GraphPad

711 Prism 7 software.

\section{ACKNOWLEDGEMENTS}

714 We thank Thomas Hart and Tristan Nowak for graph editing, and Jen Owen and Jean Tsao for 715 technical support in the protocol of tick infection in robins. We also thank Thomas Hart, Patricia 
717 and robins. We are grateful for John Leong and George Chaconas for sharing the B. burgdorferi

718 strains B31-5A4, 297, and cN40, Sudha Chaturvedi allowing us to use her Bead Homogenizer,

719 Susan Madison-Antenucci allowing us to use her fluorescence microscope, and Noel Espina for

720 the assistance with that microscope. We thank Wadsworth Media \& Tissue Culture Core for

721 preparation of Borrelia and American robin and white-footed mouse fibroblast culture medium.

722 This work was supported by NSF IOS-1755370 (DMT, MC and MDW), NSF-IOS1755286 (YL,

723 ADII, ALM, JS, and LDK), New York State Department of Health Wadsworth Center Start-Up

724 Grant (ALM and YL). The funders had no role in study design, data collection and analysis, 725 decision to publish, or preparation of the manuscript. The authors declare that the research was 726 conducted in the absence of any commercial or financial relationships that could be construed as 727 a potential conflict of interest.

729 REFERENCES

730 1. Poulin R. KBR, Morand S. Micromammals and Macroparasites. Tokyo: Springer; 2006. $731 \quad 233-56 \mathrm{p}$.

732 2. Futuyma DJ, Moreno, G. The evolution of ecological specialization. Ann Rev Ecol Syst $733 \quad 1988 ; 19: 207-33$.

734 3. Tufts DM, Hart TM, Chen GF, Kolokotronis SO, Diuk-Wasser MA, Lin YP. Outer surface 735 protein polymorphisms linked to host-spirochete association in Lyme borreliae. Molecular 736 microbiology. 2019.

737 4. Lin YP, Diuk-Wasser MA, Stevenson B, Kraiczy P. Complement Evasion Contributes to 738 Lyme Borreliae-Host Associations. Trends in parasitology. 2020;36(7):634-45. 
5. O'Keeffe KR, Oppler ZJ, Brisson D. Evolutionary ecology of Lyme Borrelia. Infection, genetics and evolution : journal of molecular epidemiology and evolutionary genetics in infectious diseases. 2020:104570. association of Borrelia burgdorferi sensu lato--the key role of host complement. Trends in

$744 \quad$ microbiology. 2002;10(2):74-9.

745 7. Kurtenbach K, Peacey M, Rijpkema SG, Hoodless AN, Nuttall PA, Randolph SE. Differential transmission of the genospecies of Borrelia burgdorferi sensu lato by game birds and small rodents in England. Applied and environmental microbiology. 1998;64(4):1169-74. Differential survival of Lyme borreliosis spirochetes in ticks that feed on birds. Infection and immunity. 2002;70(10):5893-5.

9. Hanincova K, Ogden NH, Diuk-Wasser M, Pappas CJ, Iyer R, Fish D, et al. Fitness variation of Borrelia burgdorferi sensu stricto strains in mice. Applied and environmental microbiology. 2008;74(1):153-7.

10. Baum E, Hue F, Barbour AG. Experimental infections of the reservoir species Peromyscus leucopus with diverse strains of Borrelia burgdorferi, a Lyme disease agent. mBio. $756 \quad 2012 ; 3(6): \mathrm{e} 00434-12$.

757 11. Hanincova K, Kurtenbach K, Diuk-Wasser M, Brei B, Fish D. Epidemic spread of Lyme 758 borreliosis, northeastern United States. Emerging infectious diseases. 2006;12(4):604-11.

759 12. Brisson D, Dykhuizen DE. ospC diversity in Borrelia burgdorferi: different hosts are 760 different niches. Genetics. 2004;168(2):713-22. 

and transmission efficiencies of Borrelia burgdorferi ospC types in avian and mammalian wildlife. Infection, genetics and evolution : journal of molecular epidemiology and evolutionary genetics in infectious diseases. 2014;27:594-600. processes in the evolutionary ecology of Lyme borreliosis. Nature reviews Microbiology. 2006;4(9):660-9.

15. Haven J, Magori K, Park AW. Ecological and inhost factors promoting distinct parasite life-history strategies in Lyme borreliosis. Epidemics. 2012;4(3):152-7. genetic study of Borrelia burgdorferi sensu stricto from eastern Long Island, New York, suggested frequency-dependent selection, gene flow and host adaptation. Hereditas. 1997;127(3):203-16. spirochete (Borrelia burgdorferi) and its shared history with tick vector (Ixodes scapularis) in the Northeastern United States. Genetics. 2002;160(3):833-49.

18. Brisson D, Dykhuizen DE, Ostfeld RS. Conspicuous impacts of inconspicuous hosts on the Lyme disease epidemic. Proc Biol Sci. 2008;275(1631):227-35.

778 19. Brisson D, Baxamusa N, Schwartz I, Wormser GP. Biodiversity of Borrelia burgdorferi 779 strains in tissues of Lyme disease patients. PloS one. 2011;6(8):e22926.

780 20. Xu Q, Seemanapalli SV, McShan K, Liang FT. Constitutive expression of outer surface 781 protein $\mathrm{C}$ diminishes the ability of Borrelia burgdorferi to evade specific humoral immunity. 782 Infection and immunity. 2006;74(9):5177-84. 

immunity. 2006;74(6):3554-64. immunity. 2004;72(10):5759-67.

790 for within-host interactions in the maintenance of antigenic diversity? Am Nat. 2013;181(4):54579154.

792 24. Brisson D, Dykhuizen DE. A modest model explains the distribution and abundance of 793 Borrelia burgdorferi strains. The American journal of tropical medicine and hygiene. $794 \quad 2006 ; 74(4): 615-22$.

795 25. Haven J, Vargas LC, Mongodin EF, Xue V, Hernandez Y, Pagan P, et al. Pervasive 796 recombination and sympatric genome diversification driven by frequency-dependent selection in 797 Borrelia burgdorferi, the Lyme disease bacterium. Genetics. 2011;189(3):951-66.

798 26. Woolhouse ME, Taylor LH, Haydon DT. Population biology of multihost pathogens. 799 Science. 2001;292(5519):1109-12.

800 27. Gog JR, Grenfell BT. Dynamics and selection of many-strain pathogens. Proceedings of 801 the National Academy of Sciences of the United States of America. 2002;99(26):17209-14.

802 28. Barrett LG, Thrall PH, Burdon JJ, Linde CC. Life history determines genetic structure and 803 evolutionary potential of host-parasite interactions. Trends Ecol Evol. 2008;23(12):678-85. 
804

805

806

807

808

809

810

811

812

813

814

815

816

817

818

819

820

821

822

823

824

825

29. Barthold SW, Persing DH, Armstrong AL, Peeples RA. Kinetics of Borrelia burgdorferi dissemination and evolution of disease after intradermal inoculation of mice. The American journal of pathology. 1991;139(2):263-73.

30. Hart T, Nguyen NTT, Nowak NA, Zhang F, Linhardt RJ, Diuk-Wasser M, et al. Polymorphic factor H-binding activity of CspA protects Lyme borreliae from the host complement in feeding ticks to facilitate tick-to-host transmission. PLoS pathogens. 2018;14(5):e1007106.

31. Frye AM, Hart TM, Tufts DM, Ram S, Diuk-Wasser MA, Kraiczy P, et al. A soft tick Ornithodoros moubata salivary protein $\mathrm{OmCI}$ is a potent inhibitor to prevent avian complement activation. Ticks and tick-borne diseases. 2020;11(2):101354.

32. Finnie JA, Stewart RB, Aston WP. A comparison of cobra venom factor-induced depletion of serum C3 in eight different strains of mice. Dev Comp Immunol. 1981;5(4):697-701.

33. Ivanova L, Christova I, Neves V, Aroso M, Meirelles L, Brisson D, et al. Comprehensive seroprofiling of sixteen B. burgdorferi OspC: implications for Lyme disease diagnostics design. Clinical immunology. 2009;132(3):393-400.

34. States SL, Brinkerhoff RJ, Carpi G, Steeves TK, Folsom-O'Keefe C, DeVeaux M, et al. Lyme disease risk not amplified in a species-poor vertebrate community: similar Borrelia burgdorferi tick infection prevalence and OspC genotype frequencies. Infection, genetics and evolution : journal of molecular epidemiology and evolutionary genetics in infectious diseases. 2014;27:566-75.

35. Wormser GP, Brisson D, Liveris D, Hanincova K, Sandigursky S, Nowakowski J, et al. Borrelia burgdorferi genotype predicts the capacity for hematogenous dissemination during early Lyme disease. The Journal of infectious diseases. 2008;198(9):1358-64. 
36. Jones KL, Glickstein LJ, Damle N, Sikand VK, McHugh G, Steere AC. Borrelia burgdorferi genetic markers and disseminated disease in patients with early Lyme disease. Journal of clinical microbiology. 2006;44(12):4407-13.

37. Wang G, Ojaimi C, Wu H, Saksenberg V, Iyer R, Liveris D, et al. Disease severity in a murine model of lyme borreliosis is associated with the genotype of the infecting Borrelia burgdorferi sensu stricto strain. The Journal of infectious diseases. 2002;186(6):782-91.

38. Parveen N, Robbins D, Leong JM. Strain variation in glycosaminoglycan recognition influences cell-type-specific binding by lyme disease spirochetes. Infection and immunity. 1999;67(4):1743-9.

39. Zipfel PF, Skerka C. Complement regulators and inhibitory proteins. Nature reviews Immunology. 2009;9(10):729-40.

40. Sjoberg AP, Trouw LA, Blom AM. Complement activation and inhibition: a delicate balance. Trends in immunology. 2009;30(2):83-90.

41. Tracy KE, Baumgarth N. Borrelia burgdorferi Manipulates Innate and Adaptive Immunity to Establish Persistence in Rodent Reservoir Hosts. Frontiers in immunology. 2017;8:116.

42. Hyde JA. Borrelia burgdorferi Keeps Moving and Carries on: A Review of Borrelial Dissemination and Invasion. Frontiers in immunology. 2017;8:114.

43. Liu N, Montgomery RR, Barthold SW, Bockenstedt LK. Myeloid differentiation antigen 88 deficiency impairs pathogen clearance but does not alter inflammation in Borrelia burgdorferiinfected mice. Infection and immunity. 2004;72(6):3195-203.

44. Bolz DD, Sundsbak RS, Ma Y, Akira S, Kirschning CJ, Zachary JF, et al. MyD88 plays a unique role in host defense but not arthritis development in Lyme disease. Journal of immunology. 2004;173(3):2003-10. 
45. Troy EB, Lin T, Gao L, Lazinski DW, Camilli A, Norris SJ, et al. Understanding barriers to Borrelia burgdorferi dissemination during infection using massively parallel sequencing. Infection and immunity. 2013;81(7):2347-57.

46. Strle K, Jones KL, Drouin EE, Li X, Steere AC. Borrelia burgdorferi RST1 (OspC type A) genotype is associated with greater inflammation and more severe Lyme disease. The American journal of pathology. 2011;178(6):2726-39.

47. Cerar T, Strle F, Stupica D, Ruzic-Sabljic E, McHugh G, Steere AC, et al. Differences in Genotype, Clinical Features, and Inflammatory Potential of Borrelia burgdorferi sensu stricto Strains from Europe and the United States. Emerging infectious diseases. 2016;22(5):818-27.

48. Petzke MM, Iyer R, Love AC, Spieler Z, Brooks A, Schwartz I. Borrelia burgdorferi induces a type I interferon response during early stages of disseminated infection in mice. BMC microbiology. 2016;16:29.

49. Mason LM, Herkes EA, Krupna-Gaylord MA, Oei A, van der Poll T, Wormser GP, et al. Borrelia burgdorferi clinical isolates induce human innate immune responses that are not dependent on genotype. Immunobiology. 2015;220(10):1141-50.

50. Wang G, Petzke MM, Iyer R, Wu H, Schwartz I. Pattern of proinflammatory cytokine induction in RAW264.7 mouse macrophages is identical for virulent and attenuated Borrelia burgdorferi. Journal of immunology. 2008;180(12):8306-15.

51. Kern A, Schnell G, Bernard Q, Boeuf A, Jaulhac B, Collin E, et al. Heterogeneity of Borrelia burgdorferi Sensu Stricto Population and Its Involvement in Borrelia Pathogenicity: Study on Murine Model with Specific Emphasis on the Skin Interface. PloS one. 2015;10(7):e0133195. 
871 52. Schramm F, Kern A, Barthel C, Nadaud S, Meyer N, Jaulhac B, et al. Microarray analyses

872 of inflammation response of human dermal fibroblasts to different strains of Borrelia burgdorferi

873 sensu stricto. PloS one. 2012;7(6):e40046.

874 53. Li X, McHugh GA, Damle N, Sikand VK, Glickstein L, Steere AC. Burden and viability

875 of Borrelia burgdorferi in skin and joints of patients with erythema migrans or lyme arthritis.

876 Arthritis and rheumatism. 2011;63(8):2238-47.

877 54. Jones KL, McHugh GA, Glickstein LJ, Steere AC. Analysis of Borrelia burgdorferi 878 genotypes in patients with Lyme arthritis: High frequency of ribosomal RNA intergenic spacer 879 type 1 strains in antibiotic-refractory arthritis. Arthritis and rheumatism. 2009;60(7):2174-82.

880 55. Dykhuizen DE, Brisson D, Sandigursky S, Wormser GP, Nowakowski J, Nadelman RB, 881 et al. The propensity of different Borrelia burgdorferi sensu stricto genotypes to cause 882 disseminated infections in humans. The American journal of tropical medicine and hygiene. $883 \quad 2008 ; 78(5): 806-10$.

884 56. Barthold SW, Bockenstedt LK. Passive immunizing activity of sera from mice infected 885 with Borrelia burgdorferi. Infection and immunity. 1993;61(11):4696-702.

886 57. Fikrig E, Bockenstedt LK, Barthold SW, Chen M, Tao H, Ali-Salaam P, et al. Sera from 887 patients with chronic Lyme disease protect mice from Lyme borreliosis. The Journal of infectious 888 diseases. 1994;169(3):568-74.

889 58. Wang G, Ojaimi C, Iyer R, Saksenberg V, McClain SA, Wormser GP, et al. Impact of 890 genotypic variation of Borrelia burgdorferi sensu stricto on kinetics of dissemination and severity 891 of disease in C3H/HeJ mice. Infection and immunity. 2001;69(7):4303-12. 
59. Benoit VM, Fischer JR, Lin YP, Parveen N, Leong JM. Allelic variation of the Lyme disease spirochete adhesin DbpA influences spirochetal binding to decorin, dermatan sulfate, and mammalian cells. Infection and immunity. 2011;79(9):3501-9.

60. Roberts WC, Mullikin BA, Lathigra R, Hanson MS. Molecular analysis of sequence heterogeneity among genes encoding decorin binding proteins A and B of Borrelia burgdorferi sensu lato. Infection and immunity. 1998;66(11):5275-85.

61. Wilske B, Preac-Mursic V, Jauris S, Hofmann A, Pradel I, Soutschek E, et al. Immunological and molecular polymorphisms of OspC, an immunodominant major outer surface protein of Borrelia burgdorferi. Infection and immunity. 1993;61(5):2182-91.

62. Lin YP, Tan X, Caine JA, Castellanos M, Chaconas G, Coburn J, et al. Strain-specific joint invasion and colonization by Lyme disease spirochetes is promoted by outer surface protein $\mathrm{C}$. PLoS pathogens. 2020;16(5):e1008516.

\section{Lin YP, Benoit V, Yang X, Martinez-Herranz R, Pal U, Leong JM. Strain-specific variation} of the decorin-binding adhesin DbpA influences the tissue tropism of the lyme disease spirochete. PLoS pathogens. 2014;10(7):e1004238.

64. Isogai E, Tanaka S, Braga IS, 3rd, Itakura C, Isogai H, Kimura K, et al. Experimental Borrelia garinii infection of Japanese quail. Infection and immunity. 1994;62(8):3580-2.

65. Schwan TG, Piesman J, Golde WT, Dolan MC, Rosa PA. Induction of an outer surface protein on Borrelia burgdorferi during tick feeding. Proceedings of the National Academy of Sciences of the United States of America. 1995;92(7):2909-13.

66. Hodzic E, Feng S, Freet KJ, Borjesson DL, Barthold SW. Borrelia burgdorferi population kinetics and selected gene expression at the host-vector interface. Infection and immunity. 2002;70(7):3382-8. 
915

916

917

918

919

920

921

922

923

924

925

926

927

928

929

930

931

932

933

934

935

936

67. Hodzic E, Feng S, Freet KJ, Barthold SW. Borrelia burgdorferi population dynamics and prototype gene expression during infection of immunocompetent and immunodeficient mice. Infection and immunity. 2003;71(9):5042-55.

68. Bykowski T, Woodman ME, Cooley AE, Brissette CA, Brade V, Wallich R, et al. Coordinated expression of Borrelia burgdorferi complement regulator-acquiring surface proteins during the Lyme disease spirochete's mammal-tick infection cycle. Infection and immunity. 2007;75(9):4227-36.

69. Iyer R, Caimano MJ, Luthra A, Axline D, Jr., Corona A, Iacobas DA, et al. Stage-specific global alterations in the transcriptomes of Lyme disease spirochetes during tick feeding and following mammalian host adaptation. Molecular microbiology. 2015;95(3):509-38.

70. Zhang JR, Hardham JM, Barbour AG, Norris SJ. Antigenic variation in Lyme disease borreliae by promiscuous recombination of VMP-like sequence cassettes. Cell. 1997;89(2):27585.

71. Verhey TB, Castellanos M, Chaconas G. Analysis of recombinational switching at the antigenic variation locus of the Lyme spirochete using a novel PacBio sequencing pipeline. Molecular microbiology. 2018;107(1):104-15.

72. Coutte L, Botkin DJ, Gao L, Norris SJ. Detailed analysis of sequence changes occurring during $v l s E$ antigenic variation in the mouse model of Borrelia burgdorferi infection. PLoS pathogens. 2009;5(2):e1000293.

73. Shih CM, Telford SR, 3rd, Pollack RJ, Spielman A. Rapid dissemination by the agent of Lyme disease in hosts that permit fulminating infection. Infection and immunity. 1993;61(6):23969. 
74. Caine JA, Lin YP, Kessler JR, Sato H, Leong JM, Coburn J. Borrelia burgdorferi outer surface protein $\mathrm{C}(\mathrm{OspC})$ binds complement component $\mathrm{C} 4 \mathrm{~b}$ and confers bloodstream survival. Cellular microbiology. 2017.

75. Lagal V, Portnoi D, Faure G, Postic D, Baranton G. Borrelia burgdorferi sensu stricto invasiveness is correlated with OspC-plasminogen affinity. Microbes and infection / Institut Pasteur. 2006;8(3):645-52.

76. Rogers EA, Marconi RT. Delineation of species-specific binding properties of the CspZ protein (BBH06) of Lyme disease spirochetes: evidence for new contributions to the pathogenesis of Borrelia spp. Infection and immunity. 2007;75(11):5272-81.

77. Wallich R, Pattathu J, Kitiratschky V, Brenner C, Zipfel PF, Brade V, et al. Identification and functional characterization of complement regulator-acquiring surface protein 1 of the Lyme disease spirochetes Borrelia afzelii and Borrelia garinii. Infection and immunity. 2005;73(4):2351-9.

78. Hammerschmidt C, Koenigs A, Siegel C, Hallstrom T, Skerka C, Wallich R, et al. Versatile roles of CspA orthologs in complement inactivation of serum-resistant Lyme disease spirochetes. Infection and immunity. 2014;82(1):380-92.

79. Alitalo A, Meri T, Comstedt P, Jeffery L, Tornberg J, Strandin T, et al. Expression of complement factor $\mathrm{H}$ binding immunoevasion proteins in Borrelia garinii isolated from patients with neuroborreliosis. European journal of immunology. 2005;35(10):3043-53.

80. Xie J, Zhi H, Garrigues RJ, Keightley A, Garcia BL, Skare JT. Structural determination of the complement inhibitory domain of Borrelia burgdorferi BBK32 provides insight into classical pathway complement evasion by Lyme disease spirochetes. PLoS pathogens. 2019;15(3):e1007659. 
960

961

962

963

964

965

966

967

968

969

970

971

972

973

974

975

976

977

978

979

980

981

81. Margos G, Vollmer SA, Cornet M, Garnier M, Fingerle V, Wilske B, et al. A new Borrelia species defined by multilocus sequence analysis of housekeeping genes. Applied and environmental microbiology. 2009;75(16):5410-6.

82. Norte AC, Margos G, Becker NS, Albino Ramos J, Nuncio MS, Fingerle V, et al. Host dispersal shapes the population structure of a tick-borne bacterial pathogen. Mol Ecol. 2019.

83. Barbour AG. Isolation and cultivation of Lyme disease spirochetes. The Yale journal of biology and medicine. 1984;57(4):521-5.

84. Marcinkiewicz AL, Dupuis AP, 2nd, Zamba-Campero M, Nowak N, Kraiczy P, Ram S, et al. Blood treatment of Lyme borreliae demonstrates the mechanism of CspZ-mediated complement evasion to promote systemic infection in vertebrate hosts. Cellular microbiology. 2019;21(2):e12998.

85. Purser JE, Norris SJ. Correlation between plasmid content and infectivity in Borrelia burgdorferi. Proceedings of the National Academy of Sciences of the United States of America. 2000;97(25):13865-70.

86. Blevins JS, Hagman KE, Norgard MV. Assessment of decorin-binding protein A to the infectivity of Borrelia burgdorferi in the murine models of needle and tick infection. BMC microbiology. 2008;8:82.

87. Chan K, Casjens S, Parveen N. Detection of established virulence genes and plasmids to differentiate Borrelia burgdorferi strains. Infection and immunity. 2012;80(4):1519-29.

88. Marcinkiewicz AL, Lieknina I, Yang X, Lederman PL, Hart TM, Yates J, et al. The Factor H-Binding Site of CspZ as a Protective Target against Multistrain, Tick-Transmitted Lyme Disease. Infection and immunity. 2020;88(5). 
982

983

984

985

986

987

988

989

990

991

992

993

994

995

996

997

998

999

1000

1001

1002

1003

89. Izuogu AO, McNally KL, Harris SE, Youseff BH, Presloid JB, Burlak C, et al. Interferon signaling in Peromyscus leucopus confers a potent and specific restriction to vector-borne flaviviruses. PloS one. 2017;12(6):e0179781.

90. Calhoon EA, Miller, M. K., Jimenez, A. G., Harper, J. M., Williams, J. B. . Changes in cultured dermal fibroblasts during early passages across five wild bird species. Canadian Journal of Zoology. 2013;91:653-9.

91. Kern A, Zhou CW, Jia F, Xu Q, Hu LT. Live-vaccinia virus encapsulation in pH-sensitive polymer increases safety of a reservoir-targeted Lyme disease vaccine by targeting gastrointestinal release. Vaccine. 2016;34(38):4507-13.

92. Johnston E, Tsao JI, Munoz JD, Owen J. Anaplasma phagocytophilum infection in American robins and gray catbirds: an assessment of reservoir competence and disease in captive wildlife. Journal of medical entomology. 2013;50(1):163-70.

93. Varkey R, Du Q, Karnell JL, Xiao X, Casey KA, Woods R, et al. Discovery and characterization of potent IL-21 neutralizing antibodies via a novel alternating antigen immunization and humanization strategy. PloS one. 2019;14(1):e0211236.

94. Lin YP, Yu Y, Marcinkiewicz AL, Lederman P, Hart TM, Zhang F, et al. Nonanticoagulant Heparin as a Pre-exposure Prophylaxis Prevents Lyme Disease Infection. ACS Infect Dis. 2020;6(3):503-14.

95. Marcinkiewicz AL, Lieknina I, Kotelovica S, Yang X, Kraiczy P, Pal U, et al. Eliminating Factor H-Binding Activity of Borrelia burgdorferi CspZ Combined with Virus-Like Particle Conjugation Enhances Its Efficacy as a Lyme Disease Vaccine. Frontiers in immunology. 2018;9:181. 
1004 96. Benjamini YK, A. M. Yekutieli, D. . Adaptive linear step-up procedures that control the 1005 false discovery rate. Biometrika. 2006;93:491-507.

1006 97. Burgdorfer W, Barbour AG, Hayes SF, Benach JL, Grunwaldt E, Davis JP. Lyme disease1007 a tick-borne spirochetosis? Science. 1982;216(4552):1317-9.

1008 98. Leong JM, Moitoso de Vargas L, Isberg RR. Binding of cultured mammalian cells to 1009 immobilized bacteria. Infection and immunity. 1992;60(2):683-6.

1010 99. Steere AC, Grodzicki RL, Kornblatt AN, Craft JE, Barbour AG, Burgdorfer W, et al. The 1011 spirochetal etiology of Lyme disease. The New England journal of medicine. 1983;308(13):733101240.

1013 100. Barthold SW, de Souza MS, Janotka JL, Smith AL, Persing DH. Chronic Lyme borreliosis 1014 in the laboratory mouse. The American journal of pathology. 1993;143(3):959-71.

1015 101. Barthold SW, Beck DS, Hansen GM, Terwilliger GA, Moody KD. Lyme borreliosis in 1016 selected strains and ages of laboratory mice. The Journal of infectious diseases. 1990;162(1):13310178.

1018 102. Sadziene A, Wilske B, Ferdows MS, Barbour AG. The cryptic ospC gene of Borrelia 1019 burgdorferi B31 is located on a circular plasmid. Infection and immunity. 1993;61(5):2192-5.

1020 103. Lin T, Oliver JH, Jr., Gao L. Genetic diversity of the outer surface protein C gene of 1021 southern Borrelia isolates and its possible epidemiological, clinical, and pathogenetic 1022 implications. Journal of clinical microbiology. 2002;40(7):2572-83.

1023 104. Wang IN, Dykhuizen DE, Qiu W, Dunn JJ, Bosler EM, Luft BJ. Genetic diversity of $\operatorname{spp} C$ 1024 in a local population of Borrelia burgdorferi sensu stricto. Genetics. 1999;151(1):15-30. 
1025 105. Chan K, Awan M, Barthold SW, Parveen N. Comparative molecular analyses of Borrelia 1026 burgdorferi sensu stricto strains B31 and N40D10/E9 and determination of their pathogenicity.

1027 BMC microbiology. 2012;12:157.

1028 106. Barbour AG, Travinsky B. Evolution and distribution of the ospC Gene, a transferable 1029 serotype determinant of Borrelia burgdorferi. mBio. 2010;1(4). 
Table 1. The number of positive xenodiagnostic larval ticks collected from robins and white-

1050 footed mice.

\begin{tabular}{ccccc}
\hline \multirow{2}{*}{ dpf $^{\text {a }}$} & \multicolumn{4}{c}{ Positive xenodiagnostic larval ticks acquired from } \\
\cline { 2 - 5 } & $\begin{array}{c}\text { Mice fed on by } \\
\text { naïve nymphs }\end{array}$ & \multicolumn{2}{c}{ Mice fed on by nymphs carrying $\boldsymbol{B}$. burgdorferi } \\
\hline American robins & & & $\mathbf{2 9 7}$ & cN40 \\
\hline $\mathbf{1 4}$ & $0 / 44$ & $39 / 44^{\mathrm{b}}$ & $19 / 44^{\mathrm{b}, \mathrm{c}}$ & $41 / 55^{\mathrm{b}}$ \\
$\mathbf{2 8}$ & $0 / 44$ & $18 / 33^{\mathrm{b}, \mathrm{c}}$ & $11 / 44^{\mathrm{b}, \mathrm{c}}$ & $46 / 55^{\mathrm{b}}$ \\
$\mathbf{3 5}$ & $0 / 44$ & $11 / 33^{\mathrm{b}, \mathrm{c}}$ & $12 / 44^{\mathrm{b}, \mathrm{c}}$ & $34 / 55^{\mathrm{b}}$ \\
$\mathbf{5 6}$ & $0 / 44$ & $8 / 33^{\mathrm{b}, \mathrm{c}}$ & $7 / 44^{\mathrm{b}, \mathrm{c}}$ & $30 / 55^{\mathrm{b}}$ \\
White-footed mice & & & & \\
$\mathbf{1 4}$ & $0 / 55$ & $47 / 55^{\mathrm{b}, \mathrm{c}}$ & $47 / 55^{\mathrm{b}, \mathrm{c}}$ & $16 / 55^{\mathrm{b}}$ \\
$\mathbf{2 8}$ & $0 / 33$ & $50 / 55^{\mathrm{b}, \mathrm{c}}$ & $40 / 55^{\mathrm{b}, \mathrm{c}}$ & $8 / 55^{\mathrm{b}}$ \\
$\mathbf{3 5}$ & $0 / 33$ & $51 / 55^{\mathrm{b}, \mathrm{c}}$ & $40 / 55^{\mathrm{b}, \mathrm{c}}$ & $9 / 55^{\mathrm{b}}$ \\
$\mathbf{5 6}$ & $0 / 33$ & $38 / 55^{\mathrm{b}, \mathrm{c}}$ & $35 / 55^{\mathrm{b}, \mathrm{c}}$ & $5 / 55^{\mathrm{b}}$ \\
\hline
\end{tabular}

1051

1052

1053

1054

1055

1056

1057

1058

1059

1060

1061

1062

1063

1064

1065

1066

\section{a Days post nymph feeding.}

${ }^{b}$ Difference compared with larvae from the mice fed on by naïve nymphs by two-tailed Fisher test. ${ }^{\mathrm{c}}$ Difference compared with larvae from the mice fed on by nymphs carrying strain cN40 by twotailed Fisher test. 


\section{FIGURE LEGENDS}

Figure 1. Borrelia burgdorferi B31-5A4, 297, and cN40 differed in early colonization in robins

fibroblasts. (A and B): (A) American robins and (B) white-footed (WF) mice were intradermally 
1090 ("Mock"). After the RNA was extracted from these cells, the expression levels of the genes

1091 encoding IFN- $\gamma$, TNF, or TNF $\alpha$-induced protein and the constitutively expressed gene, actin, and

1092 18S rRNA, from robins and white-footed mice were determined using quantitative reverse 1093 transcription polymerase chain reaction. The expression levels of the genes encoding (E and $\mathbf{H})$

1094 18S rRNA, (F and I) IFN $\gamma,(\mathbf{G})$ TNF $\alpha$-induced protein, and (J) TNF are presented by normalizing 1095 to the expression levels of the gene encoding actin. Each bar represents the mean of three 1096 independent determinations \pm SD. The asterisk (“*”) indicates significant differences $(P<0.05 ;)$

1097 in the normalized expression levels of the gene encoding IFN- $\gamma, \mathrm{TNF}$, and TNF $\alpha$-induced protein 1098 in fibroblasts treated with indicated spirochete strains relative to those in mock-treated cells.

Figure 2. Borrelia burgdorferi B31-5A4, 297, and cN40 displayed strain-to-strain variation of

1102 of infection. (B to K): Ixodes scapularis nymphs carrying B. burgdorferi B31-5A4, 297, or cN40, 1103 or naïve nymphs (Uninfect.) were allowed to feed to repletion on (B to F) 3, 4, 5, or 4 American 1104 robins, respectively, or (G to K) 5 white-footed (WF) mice per group. Approximately 100 larval ticks were placed on each robin at the time points indicated in Fig. 2A to feed till repletion. qPCR was used to determine spirochete burdens derived from 55 larvae feeding on B. burgdorferi1107 infected white-footed mice or 33, 44, 55, and 44 larvae feeding on robins fed on by nymphs 1108 carrying B31-5A4, 297, or cN40, or uninfected nymphs, respectively. (B and F) The larvae were 1109 considered xenodiagnostic positive if their spirochete burdens were greater than the threshold, the 1110 mean plus three-fold standard deviation of spirochete burdens in the uninfected group. Shown are 1111 the means \pm SEM of percent positive larvae. (C to $\mathbf{F}$ and $\mathbf{H}$ to $\mathbf{K}$ ) Shown are the geometric means $1112 \pm$ geometric standard deviation of bacterial burdens in larvae that are allowed to feed on robins or 
1113

1114

1115

1116

1117

1118

1119

1120

1121

1122

1123

1124

1125

1126

1127

1128

1129

1130

1131

1132

1133

1134

1135

white-footed (WF) mice at (C and H) 14, (D and I) 28, (E and J) 35, and (F and K) 56 days post nymph feeding $(\mathrm{dpf})$. Significant differences $(\mathrm{p}<0.05)$ in the spirochete burdens relative to larvae feeding on naïve robins or white-footed mice (“*')) or between different groups (“\#”) are indicated.

Figure 3. Borrelia burgdorferi B31-5A4, 297, and cN40 differed in their ability to induce bacteremia and colonize tissues in robins and white-footed mice. Ixodes scapularis nymphs carrying B. burgdorferi B31-5A4, 297, or cN40, or naïve nymphs (Uninfect.) were allowed to feed to repletion on (A to $\mathbf{D}$ and $\mathbf{I}$ to $\mathbf{L}) 3,4,5$, and 4 American robins, respectively, or (E to $\mathbf{H}$ and $\mathbf{M}$ to $\mathbf{P}) 5$ white-footed (WF) mice per group. The bacterial loads in the blood at (A and E) 7, (B and F) 14, (C and G) 21, and (D and H) 28 days post nymph feeding (dpf) and in (I) skin, (J) heart, (K) brain, and (L) liver of robins and (M) ears, $(\mathbf{N})$ tibiofemoral joints (Tibio.), (O) heart, (P) bladder of white-footed mice at 64 days post nymph feeding (dpf) were determined by qPCR.

The bacterial loads in blood were normalized to $100 \mathrm{ng}$ total DNA. Shown are the geometric mean \pm geometric standard deviation of indicated number of robins or white-footed mice. Significant differences $(\mathrm{p}<0.05)$ in the spirochete burdens relative to robins or white-footed mice fed on by naïve nymphs (“**') are indicated.

Figure 4. Borrelia burgdorferi B31-5A4, 297, and cN40 varied in their ability to survive in robin but not white-footed mouse sera. A high passage, non-infectious, serum sensitive $B$. burgdorferi strain B313 (“B313”) or B. burgdorferi B31-5A4, 297, or cN40 were incubated for 4 $\mathrm{h}$ with the sera from American robins at a final concentration of $40 \%$ in the (A) absence or (B) presence of $2 \mu \mathrm{M}$ of OmCI. Each of these spirochete strains was also incubated for $4 \mathrm{~h}$ with the 
sera from white-footed (WF) mice at a final concentration of $40 \%$ in the (C) absence or (D) presence of $2 \mu \mathrm{M}$ of CVF. The above-mentioned sera were also heat-inactivated and included as controls. The number of motile spirochetes was assessed microscopically. The percentage of survival for $B$. burgdorferi was calculated using the number of mobile spirochetes at $4 \mathrm{~h}$ post incubation normalized to that prior to the incubation with serum. The assays were performed at three independent occasions; within each experiment, samples were run in triplicate, and the survival percentage for each experiment was calculated by averaging the results from triplicate runs. The result shown here are the average \pm standard deviation of the survival percentage from three independent experiments. Significant differences $(\mathrm{P}<0.05)$ of the percent survival of spirochetes between groups are indicated (\#).

Figure 5. Borrelia burgdorferi B31-5A4, 297, and cN40 triggered different levels of proinflammatory cytokines at early stages of robin and white-footed mice infection. Ixodes scapularis nymphs infected with B. burgdorferi B31-5A4, 297, cN40, or naïve nymphs (Uninfect.) were allowed to feed to repletion on (A to $\mathbf{H})$ American robins or (I to P) white-footed (WF) mice. The sera were obtained (A, E, I, and $\mathbf{M})$ prior to tick feeding or at $(\mathbf{B}, \mathbf{F}, \mathbf{J}$, and $\mathbf{N})$ 7-, $(\mathbf{C}, \mathbf{G}, \mathbf{K}$, and O) 14-, or (D, H, L, and P) 21-days post nymph feeding (“dpf”). The levels of IFN $\gamma$ (A to D and $\mathbf{I}$ to $\mathbf{L}$ ) and TNF $\alpha$ ( $\mathbf{E}$ to $\mathbf{H}$ and $\mathbf{M}$ to $\mathbf{P}$ ) were determined using quantitative ELISA. Shown are the geometric mean \pm geometric standard deviation of five white-footed mice per group or robins $(3,4,5$, and 4 for the strains B31-5A4-, 297-, cN40-infected robins or uninfected robins per group, respectively). Significant differences $(\mathrm{p}<0.05)$ in the cytokine levels relative to robins or white-footed mice fed on by naïve nymphs (“'*’’) are indicated. 

or (E and J) 28-days post nymph feeding (“dpf"). The levels of IgG against the mixture of $B$. 
1182 pairs could not be determined because no robust killing was observed, resulting in curves that did

1183 not fit (N.F.).

1184

1185 Figure 7. The schematic diagram showing the model supported by this study. Upon $B$.

1186 burgdorferi transmission from ticks to hosts, multiple cellular and immunological mechanisms

1187 may play in concert to determine the fitness of spirochetes in hosts. These mechanisms include the

1188 ability of B. burgdorferi to attach to cells or tissues (spirochete adhesiveness) and escape from host

1189 immune clearance (early host defense), such as complement, cytokine-mediated responses, and

1190 antibodies. Both mechanisms applied on spirochetes would lead to host specialization, resulting in

1191 the association of B. burgdorferi with particular hosts (i.e. mammal or avian specialists).

1192

1193

1194

1195

1196

1197

1198

1199

1200

1201

1202

1203

1204 
Fig. 1
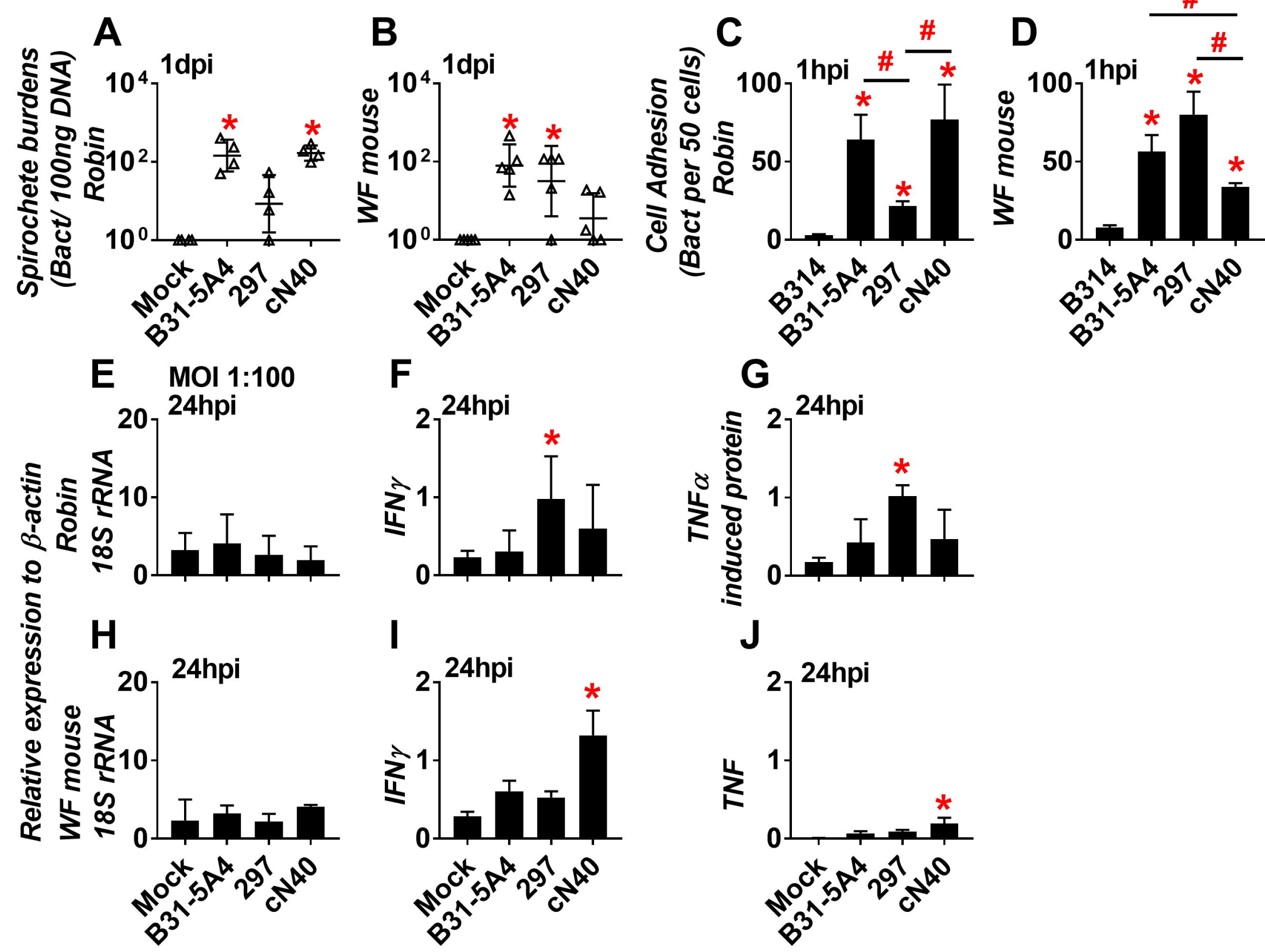
Fig. 3

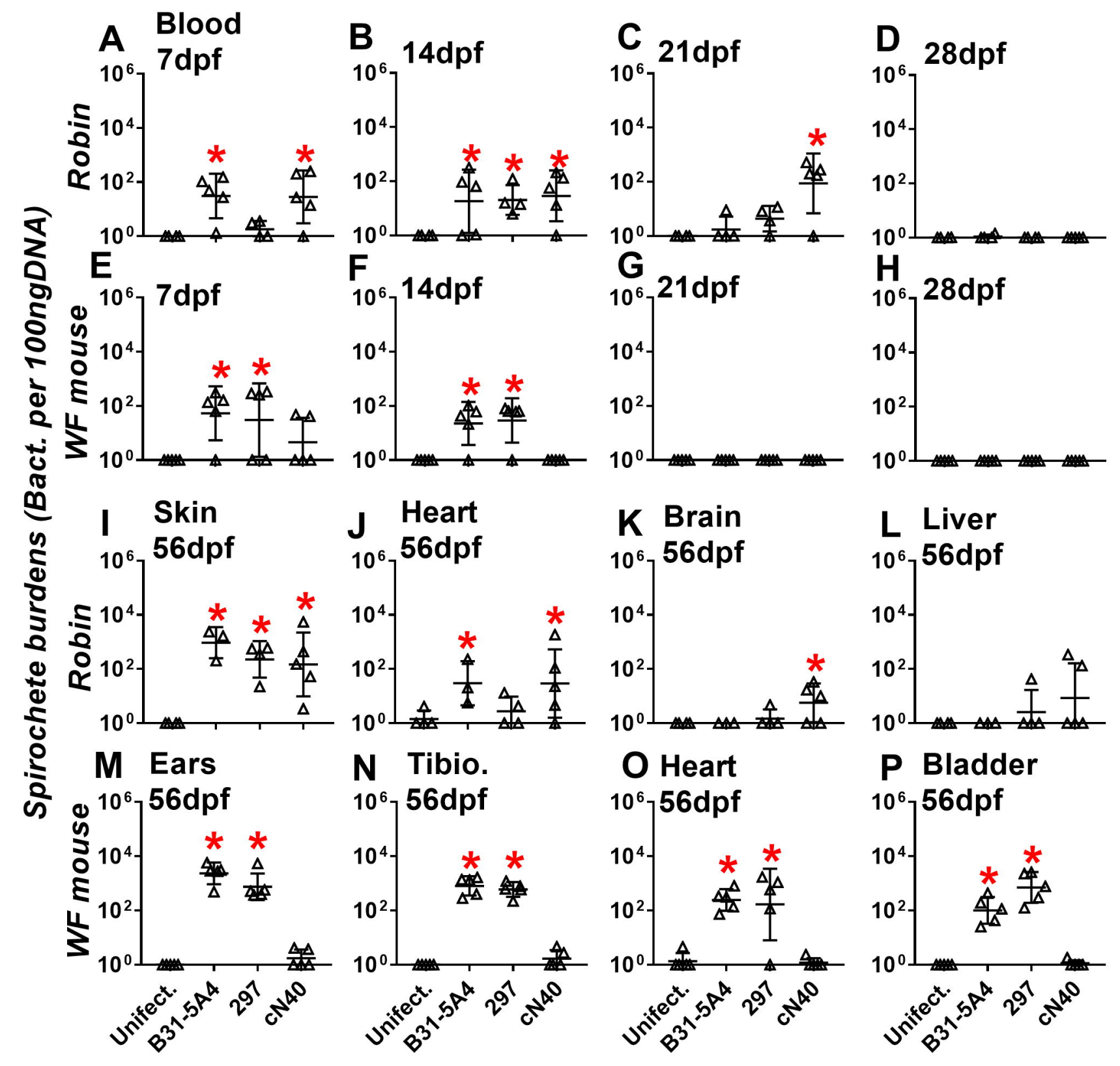


Fig. 4

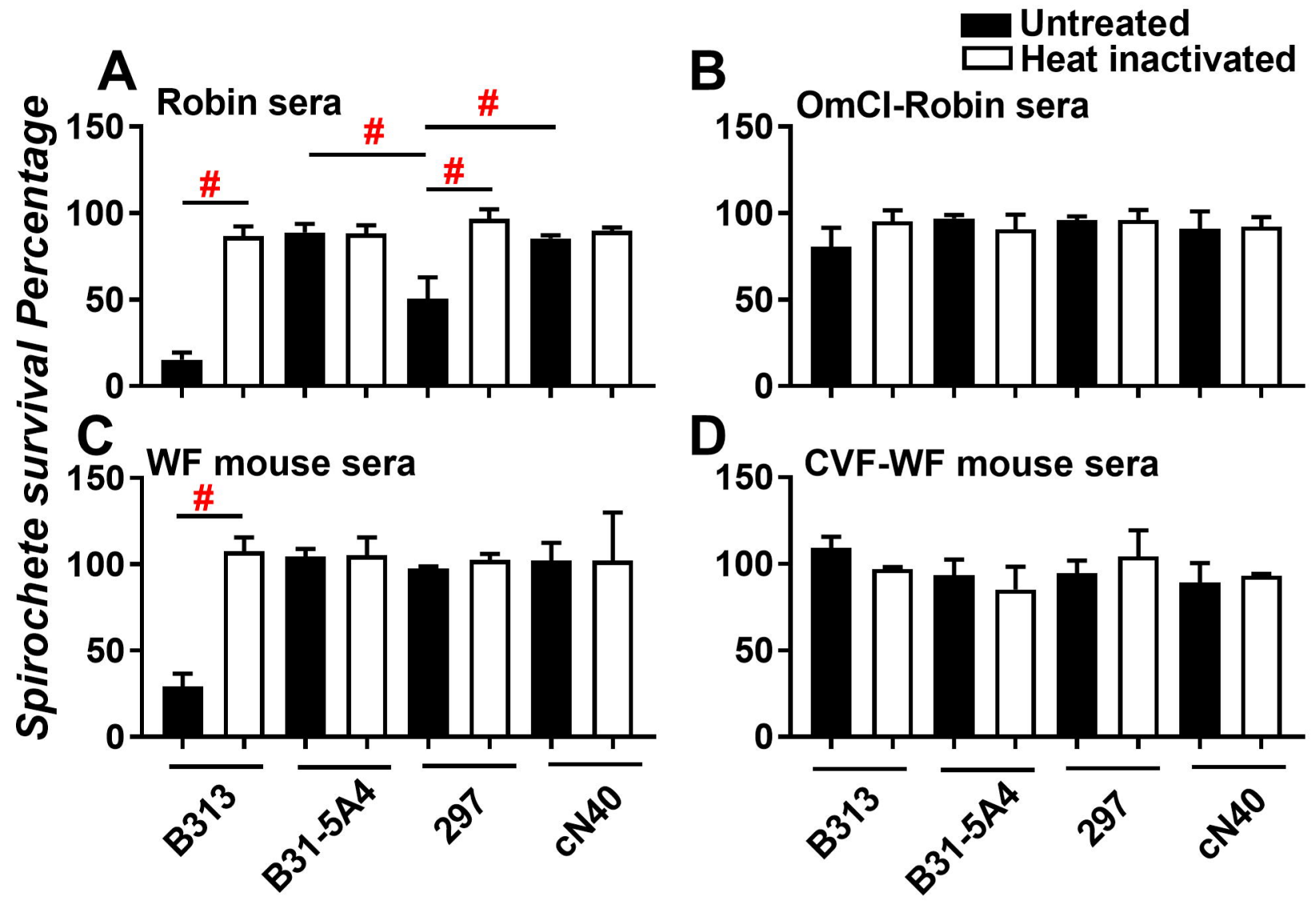


Fig. 5
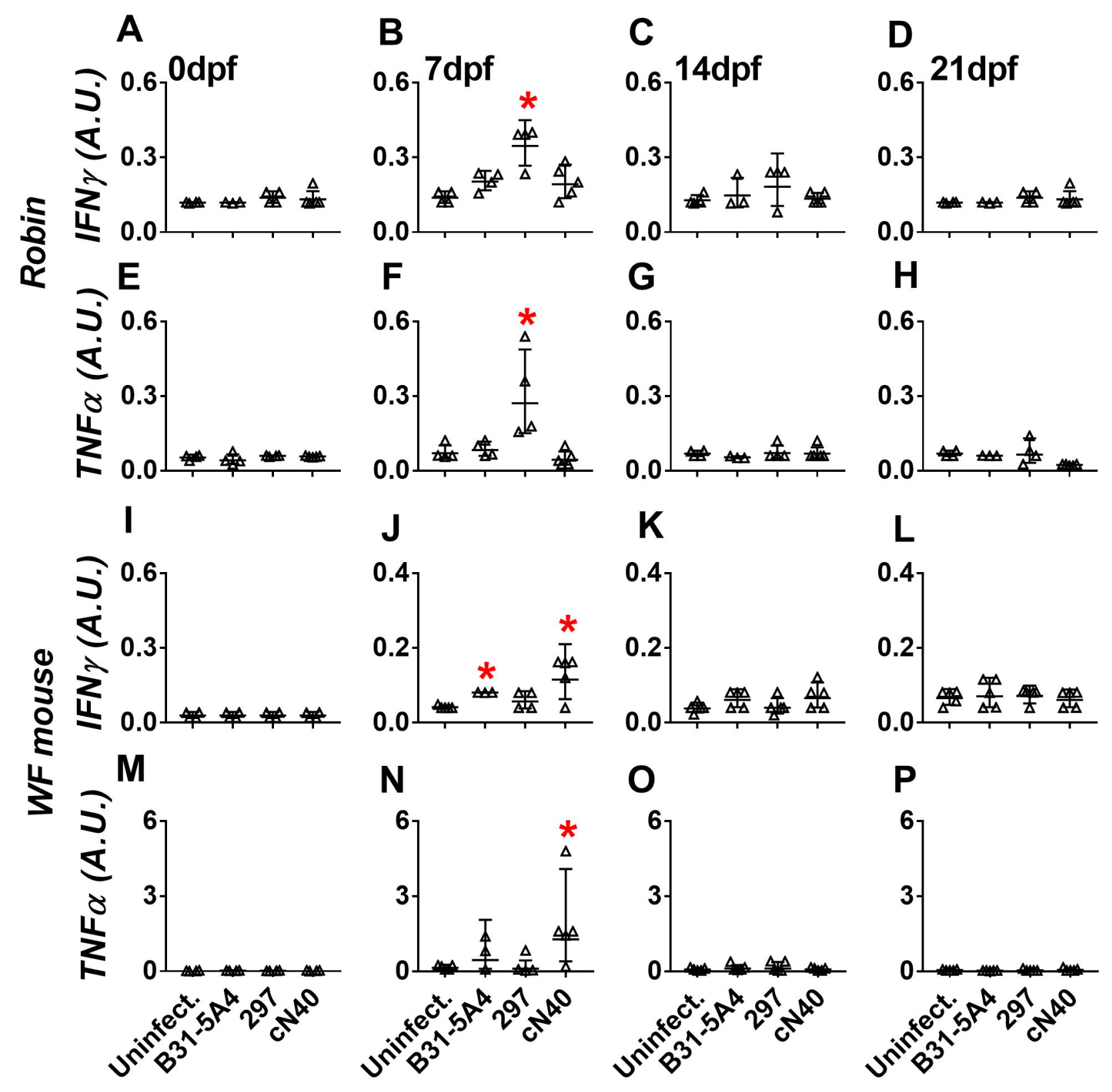
Fig. 6
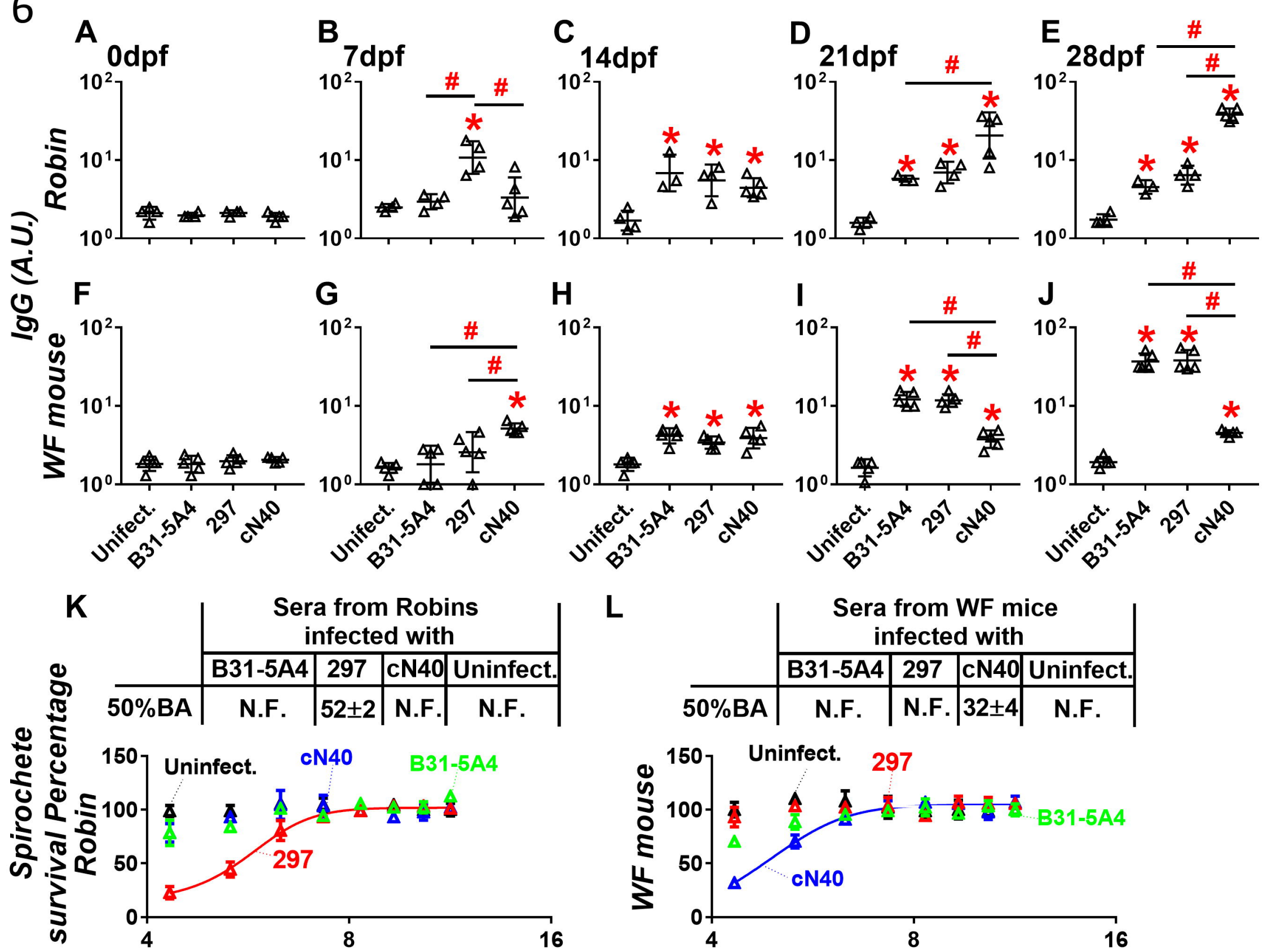

L $\quad$ Sera from WF mice \begin{tabular}{c|c|c|c|c|} 
& \multicolumn{3}{|c|}{ infected with } \\
\cline { 2 - 5 } & B31-5A4 & 297 & cN40 & Uninfect. \\
\hline $50 \%$ BA & N.F. & N.F. & $32 \pm 4$ & N.F.
\end{tabular}

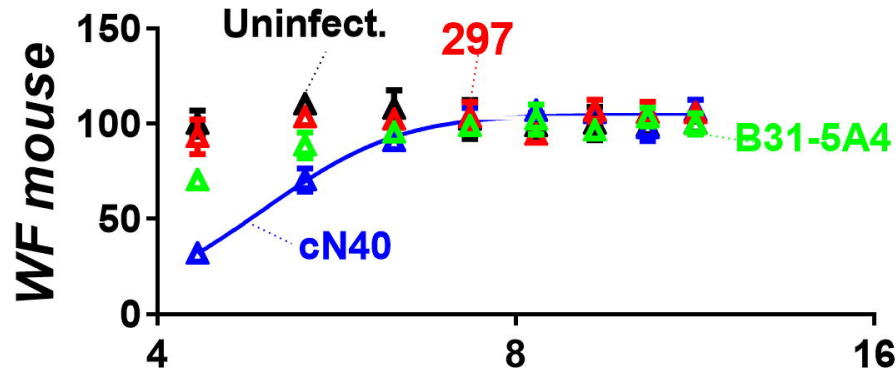

Dilution rate (Log-2 transform) 
Fig. 7

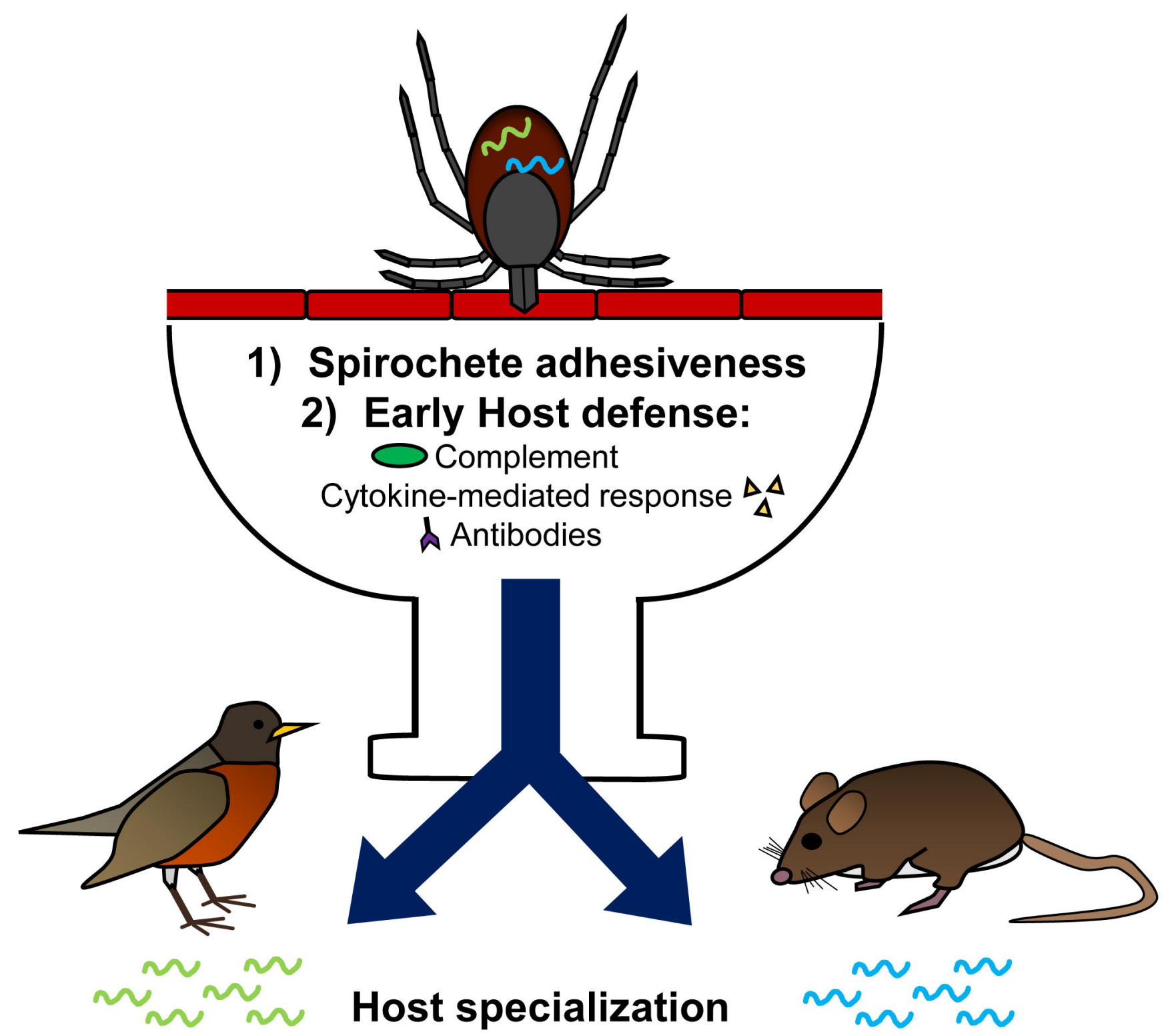

Avian specialist

Mammalian specialist 